\title{
Análise da resistência à compressão do concreto em estruturas acabadas com vistas à revisão da segurança estrutural
}

\author{
P. Helene ${ }^{1}$
}

${ }^{1}$ Universidade de São Paulo. Rua Visconde de Ouro Preto 201. São Paulo SP.

\section{Información del artículo DOI: \\ http://dx.doi.org/10.21041/ra.v1 \\ $\underline{\text { i1. } 7}$ \\ Artículo recibido el 30 de Noviembre de 2010, revisado bajo las políticas de publicación de la Revista ALCONPAT y aceptado el 15 de Enero de 2011. Cualquier discusión, incluyendo la réplica de los autores se publicará en el tercer número del año siempre y cuando la información se reciba antes del cierre del segundo número del año 2011}

\section{(C) 2011 Alconpat Internacional}

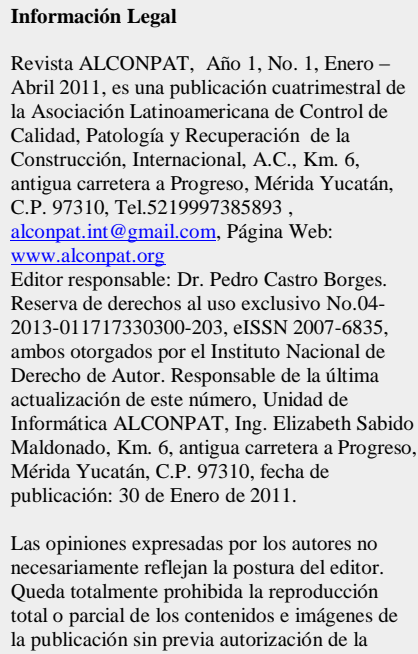

\section{RESUMO}

Trata-se de discutir a complexa problemática de medida e avaliação da resistência do concreto em estruturas acabadas, ou seja, em estruturas ou componentes estruturais já moldados in loco ou pré-fabricados, em obras em construção ou construídas há anos, para fins de revisão da segurança dessa estrutura. Inicia-se por uma sintética revisão dos conceitos de introdução da segurança no projeto das estruturas de concreto com o significado dos coeficientes de minoração da resistência dos materiais. A partir de resultados experimentais obtidos em teses de doutoramento discute-se a ordem de grandeza da influência de certas variáveis aleatórias principais. Na sequiências trata-se da representatividade da amostragem e cuidados com a extração dos testemunhos cilíndricos. A questão do crescimento da resistência com a idade e do decréscimo dessa resistência com a carga de longa duração (efeito Rüsch) também são abordados para encerrar propondo um procedimento adequado de obtenção do $f_{c k}$ para fins de revisão da segurança do projeto estrutural.

Palavras chave: resistência do concreto; testemunhos; concreto endurecido; interpretação de resistência de testemunhos; ensaios.

Autor de contacto: Paulo Helene (paulo.helene@ concretophd.com.br) 
Revista ALCONPAT, Volumen 1, Número 1, Enero-Abril 2011, Páginas 64 - 89

\section{INTRODUÇÃO}

Este documento trata da complexa questão de análise da resistência à compressão do concreto em estruturas acabadas.

Complexa porque envolve, indiretamente, a questão da segurança e durabilidade das estruturas de concreto que dependem, entre outros fatores, da resistência à compressão do concreto.

Complexa porque envolve em sua análise a participação de diferentes profissionais, tecnologistas, calculistas, ensaios de laboratório e de campo, ou seja, equipes multidisciplinares.

O método de cálculo semi-probabilista adotado no Brasil e outros países através de textos normativos consagrados do tipo ACI 318; NBR 6118 e EUROCODE 2, entre outros, adota coeficientes parciais de segurança: majoração das ações por um lado e de minoração da resistência dos materiais por outro.

Portanto a resistência efetiva do concreto à compressão, à tração e ao cisalhamento, na estrutura acabada, tem implicação direta com a estabilidade, segurança e durabilidade dessa estrutura sendo indispensável saber interpretar os resultados obtidos a partir de testemunhos.

Analisar a segurança de uma estrutura acabada é muito mais complexo que introduzir a segurança no projeto de uma estrutura nova. No escritório o projetista admite que as variáveis da obra se comportam de forma homogênea e de acordo com a teoria. Para tal toma como referência de cálculo um valor convencional muito bem definido nas normas, que é a resistência à compressão de um corpo-de-prova amostrado, moldado e ensaiado em condições ideais.

Uma vez a estrutura acabada ou o concreto endurecido, há necessidade de uma inspeção e vistoria criteriosa, pois no coeficiente de minoração da resistência do concreto entra o prumo, a excentricidade, os ninhos de concretagem, as diferenças de adensamento, de cura e outras e não isolada e exclusivamente somente a resistência do concreto à compressão.

Portanto essa interpretação requer, bom senso, conhecimento de tecnologia de concreto, conhecimento dos fundamentos da segurança estrutural, conhecimento do projeto, das cargas permanentes e acidentais, dos procedimentos de ensaio de campo, dos procedimentos de ensaio em laboratório, de análise dos resultados, etc.

Neste texto procura-se tratar do tema em profundidade e é preciso esclarecer que:

1. A segurança está baseada no fato do concreto poder apresentar até $5 \%$ do volume total entregue com resistência característica à compressão, abaixo do $f_{c k}$ especificado no projeto estrutural $^{1}$ Portanto essa produção de concreto que apresente até $5 \%$ de defeituosos estará conforme com o especificado e esperado;

2. Sabendo onde está esse concreto "conforme" porém com $f_{c k . e s t}$ abaixo do $f_{c k}$, é possível analisar caso a caso para avaliar se passa ou não do ponto de vista da capacidade resistente da estrutura, melhor dito, da capacidade resistente de cada um dos componentes estruturais moldados com esse concreto de resistência abaixo do $f_{c k}$;

3. Em geral também é importante analisar as implicações na durabilidade e vida útil e neste caso vale o mesmo raciocínio de segurança. Caso a caso. Por exemplo, se é um edifício e esse problema ocorreu nos pilares internos, não há o que preocupar-se. Se ocorreu nos pilares da garagem, já é um problema e exigirá uma proteção superficial extra;

4. Caso a quantidade de lotes de concreto com resistência abaixo do $\boldsymbol{f}_{c k}$ de projeto, superar $5 \%$ do volume total entregue, então fica claramente identificado que há um problema de produção desse concreto. A solução será negociar com a Empresa de Concreto e se for o caso substituí-la. Neste caso não haverá dúvidas de quem deve pagar as despesas e prejuízos decorrentes;

5. No caso anterior (item 3 ) de produção conforme, se por azar e lei de "Murphy" aqueles 5\% de concreto abaixo de $f_{c k}$ foram destinados justamente à concretagem de peças 
importantes ${ }^{2}$ e sem folga de capacidade resistente, não há dúvida que deve haver reforço, porém há dúvida de quem paga a conta, pois $5 \%$ de defeituosos está dentro das "regras do jogo";

Concluindo há necessidade de separar dois conceitos importantes: por um lado "produção de concreto conforme" e por outro "segurança e vida útil" da estrutura ou daqueles componentes estruturais. Sempre que houver controle efetivo e rigoroso e for detectado lote com $f_{\text {ck,est }}$ abaixo de $f_{c k}$, deve haver análise estrutural e, se necessário, extração, inspeção, ensaio de testemunhos, etc.

Por outro lado, deixando um pouco de falar de resistência dos materiais (no caso do concreto), pode-se afirmar que as diferenças de aproximação nos cálculos estruturais pode superar esses $5 \%$ de resistências do concreto abaixo do $f_{c k}$.

Imagine-se que um profissional seja contratado para verificar um projeto de um Colega que utilizou um determinado software, com recursos limitados tipo CypeCad, Montoya, SAP, e outros. Imagine também que este profissional adotou simplificações permitidas por normas.

Considere-se, então, que o Revisor utilize uma ferramenta mais precisa, utilize um método dos elementos finitos, ou um soft com mais recursos tipo por exemplo Strap, com muitos recursos de flexibilização das ligações, transferência de esforços das barras das lajes para o pórtico espacial no modelo integrado (Modelo IV), ou ainda empregue o método probabilista completo que corresponderia ao melhor caminho para otimizar o projeto de uma estrutura de concreto, apesar de muito mais complexo ${ }^{3}$.

Após semanas de análises, começa a comparar os resultados. Será que esses resultados terão diferenças menores que os citados $5 \%$ em relação ao projeto do primeiro Calculista contratado? Será que essas diferenças implicarão a necessidade de reforço estrutural? Será que eventuais discrepâncias justificam uma tolerância zero em relação ao projeto original? Será que essas diferenças significam que a estrutura não está segura ou não vai ter aquela vida útil desejada?

Isso tudo ainda sem entrar no mérito das diferenças resultantes dos métodos de análise de $2^{\mathrm{a}}$ ordem, simplificações de modelagem e dos valores dos coeficientes de ponderação das ações adotados, que tanto podem ser tomados como um valor único, ou como agrupado, ou separados individualmente pela origem dos carregamentos.

Alguns engenheiros de projeto, de obra ou mesmo de tecnologia do concreto, ainda crêem que a engenharia civil de estruturas é uma disciplina exata, na qual é possível, por uma simples penada, exigir tolerância zero.

Sabe-se ser impossível tolerância zero no Projeto, assim como numa produção de concreto. Imagine que o Brasil institua a revisão de projeto estrutural por terceira parte como obrigatória e o revisor adote tolerância zero. O que poderia ocorrer?

Sabe-se que os modelos de cálculo, os materiais, os equipamentos e a mão-de-obra, assim como os controles estão sujeitas a variáveis aleatórias e como tal são atividades passíveis de erros, de simplificações e de diferentes interpretações uma vez que um engenheiro deve conciliar muitas informações, dados e variáveis e ações às vezes imponderáveis.

Portanto bom senso é fundamental numa análise de obra acabada. A detecção de uma não conformidade é fundamental, assim como sua análise e sua correção, mas nem sempre isso significa estar "fazendo algo errado".

Sabe-se por exemplo que $10 \%$ a menos de resistência à compressão num concreto ${ }^{4}$ para laje e para viga, seja concreto armado ou protendido, resulta numa redução da capacidade resistente dessas peças de apenas $2,5 \% 5$ y 6 .

Diferenças dessa ordem na capacidade resistente de um componente estrutural podem ser perfeitamente absorvidas pelas diferenças geométricas impostas pela arquitetura, pelos arredondamentos impostos pelo cálculo da taxa de armadura, pelos arredondamentos impostos pela simetria das armaduras nas peças, pelos arredondamentos impostos pelas restrições das 
Revista ALCONPAT, Volumen 1, Número 1, Enero-Abril 2011, Páginas 64 - 89

bitolas comerciais disponíveis no mercado para serem utilizadas como armadura, pelas simplificações que são admitidas na variabilidade dos materiais, etc.

Portanto "produção de concreto em conformidade" não é o mesmo que "segurança e vida útil" e,

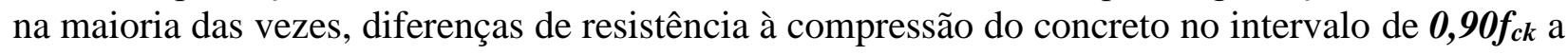
$\mathbf{0 , 9 9} f_{c k}$ não requerem reforço estrutural ou qualquer outra intervenção.

\section{CONTROLE DO CONCRETO}

O documento técnico nacional que melhor se aplica à análise deste caso, é a norma técnica brasileira "NB 1. Projeto de Estruturas de Concreto. Procedimento" publicado pela ABNT e reconhecido pelo INMETRO, como NBR 6118:2007.

Outros documentos normativos nacionais e internacionais também se aplicam, considerados como subordinados ou complementares à NBR 6118:2007, tais como ACI 318, EUROCODE, etc. Também a NBR14931:2004 Execução de Estruturas de Concreto. Procedimento, estabelece no Item 5.3.1 Requisitos da qualidade do Concreto, que cabe ao Proprietário/Construtor:

"O concreto deve ser preparado e atender aos critérios de controle da qualidade previstos na NBR 12655:2006 Concreto de cimento Portland. Preparo, controle e recebimento. Procedimento. Quando se tratar de concreto dosado em central, além dos requisitos da NBR 12655, o concreto deve ainda estar de acordo com o que estabelece a NBR 7212. No controle da qualidade dos materiais componentes do concreto deve ser obedecido o disposto na NBR 12654."

Observando ainda o item 4.4 da NBR 12655:2006 Responsável pelo recebimento do concreto, lêse:

“Os responsáveis pelo recebimento do concreto (3.2.4), são o proprietário da obra e o responsável técnico pela obra, designado pelo proprietário. A documentação comprobatória do cumprimento desta Norma (relatórios de ensaios, laudos e outros) deve estar disponível no canteiro de obra, durante toda a construção, e ser arquivada e preservada pelo prazo previsto na legislação vigente, salvo o disposto em 4.1.2"

Todo concreto entregue em obra deve ser submetido ao controle de recebimento da consistência ${ }^{7}$ e da resistência do concreto endurecido de acordo com o procedimento especificado na NBR 12655:2006. Concreto. Preparo, controle e recebimento. Procedimento, sendo sempre recomendável proceder ao controle total (100\%) com correspondente mapeamento dos locais que receberam cada concreto de um mesmo caminhão betoneira (conceito de rastreabilidade).

Esse controle, deve ser realizado pelo Proprietário/Construtor ou seu representante legal, através dos ensaios de consistência do concreto fresco $^{8}$ e retirada de amostras ${ }^{9}$ em conformidade com o método de moldagem NBR 5738:2003. Moldagem e cura de corpos-de-prova cilíndricos ou prismáticos de concreto, e devem ser sazonados, ensaiados e rompidos a 28 dias, segundo a NBR 5739:2007. Concreto. Ensaio de compressão de corpos-de-prova cilíndricos, preferencialmente, ensaiados em laboratórios credenciados e pertencentes à $\operatorname{RBLE}^{10}$.

Diversos documentos históricos e consagrados tais como ACI214 ${ }^{11}$, ACI214.4R-10 ${ }^{12}$, McIntosh ${ }^{13}$, Walker $^{14}$, Sparkes ${ }^{15}, C_{E B}{ }^{16}$, consideram, no entanto, que o controle estatístico do concreto, realizado através de amostragem parcial ou total, sempre pressupõe uma incerteza na avaliação, por mais correto que os ensaios de controle tenham sido realizados:

“...sempre haverá o risco de aceitar um concreto não conforme ou de rejeitar um concreto conforme...", chamam atenção os pesquisadores Meseguer ${ }^{17}$ e Fusco ${ }^{18}$.

Em tecnologia do concreto, o concreto dentro de um balão de um único caminhão betoneira é considerado homogêneo e tem uma única resistência conforme estabelecido pela NBR 12655:2006 na sua definição de "exemplar", que coincide com a visão de todas as demais normas internacionais. Não é possível imaginar que resultados de corpos-de-prova de uma mesma 
amassada, um mesmo volume restrito de concreto de mesmos materiais, misturados juntos e dentro de um único caminhão betoneira possam ter resistências diferentes ${ }^{19}$.

Variabilidade exagerada somente seria possível devido a outras causas relacionadas à operação inadequada, por exemplo com tempo de mistura errado, manutenção deficiente ou mau funcionamento do balão do caminhão-betoneira, ou então devido ao lançamento indevido de água extra, e nunca devido às características intrínsecas do concreto definido por um traço em peso e misturado num equipamento (balão) adequado e bem mantido.

Também, cabe ressaltar que, uma vez misturado numa betoneira ou no balão do caminhãobetoneira, o concreto resultante terá uma única resistência e esta é a sua resistência potencial na boca da bica da betoneira.

Portanto, como no caso de testemunho extraído, qualquer acontecimento posterior como transporte inadequado, mau adensamento, bicheiras, falta de cura, solicitações precoces, esmagamento por ruptura dos pilares, procedimento incorreto de extração ou de ensaio, somente vai reduzir essa resistência potencial, porém jamais aumentá-la.

Confirmada a resistência abaixo do $\boldsymbol{f}_{\boldsymbol{c}}$, através do controle por corpos-de-prova moldados, devese passar à análise efetiva desse concreto, através da extração de testemunhos.

A NBR 6118:2007 é enfática na exigência de representatividade da amostra composta por testemunhos extraídos que deve ser retirada com muito cuidado e profissionalismo e deve bem representar o lote em exame.

No caso de pilares, cada pilar deve ser representado por apenas um testemunho íntegro (exemplar $)^{20}$. Se necessário extrair mais de um testemunho num mesmo elemento estrutural moldado com concreto de mesmo lote, vale o resultado maior dos "irmãos", equivalente ao conceito em corpos-de-prova.

Preferencialmente os testemunhos devem ser extraídos após realização de ensaios esclerométricos $^{21}$ de acordo com a norma NBR 7584:1995. Concreto endurecido. Avaliação da dureza superficial pelo esclerômetro de reflexão. Método de Ensaio, e acompanhados por ensaios de pacometria de acordo com os métodos internacionais da British Standards Institute (BSI) $\rightarrow$ BS 1881 204:1988. Testing Concrete. Recommendations on the use of electromagnetic covermeters, ou do American Concrete Institute ACI 228.2R-21 Part 2 (2004) Nondestructive Test Methods for evaluation of Concrete in Structures). para evitar extrair ou cortar barras da armadura.

A seguir, a NBR 6118:2007 recomenda o uso do procedimento NBR 7680: 2007 Concreto: Extração, preparação, e ensaios de testemunhos de concreto. Procedimento, estabelecendo limites e desempenho para o equipamento de extração, diâmetro dos cálices, preferencialmente, acima de 3 vezes o diâmetro do agregado graúdo ${ }^{22}$, buscando-se sempre não cortar armadura e sazonando os testemunhos em laboratório ao ar por $48 \mathrm{~h}$ antes da ruptura, sempre que a estrutura não vá estar submersa ${ }^{23}$. Também exige que o ensaio de ruptura seja conduzido até a desagregação total do concreto e que seja registrado no relatório de ensaio a forma de ruptura dos testemunhos extraídos.

Portanto para uma análise confiável é necessário que todos esses cuidados sejam realmente tomados durante as operações de amostragem e extração dos testemunhos, além de utilizar máquinas de extração adequadas e sem "jogo" no eixo, adequada fixação à estrutura para não trepidar durante a extração, empregar coroa diamantada nova nos cálices, no caso de pilares evitar extrair mais de um testemunho e se necessário outro que seja extraído na mesma vertical e face, e outros cuidados.

As NBR 6118:2007 e NBR 7680:2006 e as normas internacionais citadas são unânimes em recomendar amostragem de testemunhos extraídos de concreto somente de regiões sãs e íntegras, sempre e quando o objetivo é avaliar a resistência à compressão do concreto. 
Revista ALCONPAT, Volumen 1, Número 1, Enero-Abril 2011, Páginas 64 - 89

Jamais poderiam ser ensaiados e utilizados testemunhos extraídos provenientes de pilares que sofreram prévio esmagamento, onde, obviamente, o concreto já estará rompido e não apresenta mais sua resistência original, ou de regiões com nítidos ninhos de concretagem, ou de regiões de juntas de concretagem, ou próximo de arestas.

Antes de romper os testemunhos, estando estes preparados e homogeneamente secos ou úmidos, estes deveriam, preferencialmente, ser submetidos ao ensaio de ultrasom em conformidade com a NBR 8802:1994 Concreto endurecido - Determinação da velocidade de propagação de onda ultra-sônica. Método de Ensaio, para verificação da uniformidade e detecção de eventuais vazios internos ou inclusão de "materiais estranhos ${ }^{24 ", ~ n a ̃ o ~ v i s i ́ v e i s . ~}$

Ensaios de caracterização físico-química do concreto, tipo massa específica, absorção de água, porosidade, análise petrográfica, módulo de elasticidade, difusibilidade de íons, condutibilidade térmica e outros podem e devem ser realizados em casos específicos a partir de testemunhos extraídos.

\section{NORMALIZAÇÃO}

È praxe admitir-se que o controle de recebimento de concreto tenha sido realizado em conformidade com o prescrito na NBR 12655:2006, obrigatório para obras e estruturas de concreto no Brasil. Essa é uma responsabilidade do Proprietário e de seu preposto, em geral a Construtora que sub-contrata um Laboratório de controle. Portanto caso esse controle de recebimento aponte resultado de resistência aquém da especificada, será necessário extrair testemunhos para avaliar, estimar, medir a resistência do concreto na estrutura.

Porém toda a teoria da segurança estrutural não está baseada no testemunho e sim no resultado do corpo-de-prova moldado. Dessa maneira é sempre necessário transformar o resultado do testemunho num resultado equivalente como se tivesse sido moldado, ou seja, a dificuldade deste tema é transformar o $f_{c, \text { ext }, j}$ num $\boldsymbol{f}_{\boldsymbol{c} \boldsymbol{k}}$ equivalente para viabilizar um novo cálculo estrutural utilizando as mesmas fórmulas e modelos que se empregam para obras novas com corpos-deprova moldados.

Apesar de parecer simples esta afirmação é conceitual, pois a maioria dos Projetistas e profissionais do setor busca encontrar qual a resistência à compressão do concreto lá na obra, quando, na verdade, há de ser buscado qual o $f_{c k}$ equivalente para viabilizar uma revisão de cálculo através dos modelos e fórmulas convencionais.

No caso de resultados de controle aparentemente aquém do especificado a NBR 6118:2007 recomenda verificação da resistência do concreto in loco, através da extração de testemunhos conforme NBR 7680:2007, com resultados analisados segundo os conceitos da NBR 12655:2006.

Por outro lado no caso da vida útil e outras características de desempenho deve-se consultar a NBR $15575^{25}$.

A resistência à compressão do concreto avaliada através de extração de testemunhos, envolve novas operações de ensaio em obra e em laboratório, passíveis de erros e de controverso entendimento, pois dependem da introdução de vários e novos coeficientes de "ajustes".

Além disso a verificação da resistência à compressão in loco, vai depender também, e muito, da qualidade da execução. Pequenas e localizadas regiões de concreto mal adensado podem conduzir a uma avaliação errônea.

$\mathrm{Na}$ maioria dos casos recomenda-se ensaios esclerométricos ${ }^{26}$ prévios para identificar a homogeneidade da execução.

Também, do ponto de vista da segurança estrutural, a NBR 8681:2003. Ações e segurança nas estruturas. Procedimento, deixa claro que o procedimento atual de introdução da segurança no projeto das estruturas em geral (metálicas, madeira, concreto e alvenaria) é semi-probabilista ou 
seja, trabalha com probabilidades de ruína e não com valores matemáticos, deterministas e exatos.

Os documentos internacionais amplamente reconhecidos tais como EUROCODE II:2004. Design of Concrete Structures; Model Code 90 da fib(CEB-FIP):1999 Bulletin n.2 v.2. Structural Concrete. Basis of Design; ACI 318:2005. Building Code Requirements for Structural Concrete e ACI 437:2003. Strength Evaluation of Existing Concrete Structures, e o mais recente fib(CEBFIP) Model Code 2010 First Complete Draft v.1 e v.2, também consideram probabilidades, ou seja, têm um arcabouço conceitual de variáveis estocásticas ou aleatórias, porém trabalham em última instância com coeficientes parciais de minoração de resistências e de majoração de ações, que acabam sendo utilizados para compensar o desconhecimento de modelos precisos que possam efetivamente representar as inúmeras variáveis decorrentes das ações (cargas), do meio ambiente, dos materiais, da execução, dos ensaios de controle e das próprias simplificações de cálculo.

No caso de existência de resultados de resistência abaixo de $f_{c k}$ de projeto, devem ser adotadas as seguintes ações corretivas, conforme NBR 6118, item 25.3.1:

a) revisão do projeto considerando o novo resultado de resistência característica do concreto à compressão obtido do controle de recebimento realizado através de corpos-de-prova moldados;

b) permanecendo a insegurança, extrair testemunhos de acordo com a NBR 7680, estimar o novo $f_{c k}$ de acordo com a NBR 12655 e utilizar na nova verificação estrutural o novo $\gamma_{c}$ disposto no item 12.4.1 da NBR 6118;

c) permanecendo a insegurança, deve ser atendido o item 25.3.3 da NBR 6118, que orienta escolher entre as seguintes alternativas:

$>$ determinar as restrições de uso da estrutura;

$>$ providenciar o projeto de reforço;

$>$ decidir pela demolição parcial ou total.

Para a reavaliação da segurança estrutural e da estabilidade global, considerando o ELU, a NBR 6118:2007 no seu item 12.4.1 recomenda que, no caso de testemunhos extraídos da estrutura, seja adotado $\gamma_{c}=\frac{\gamma_{c, \text { original }}}{\mathbf{1 , 1}}$. Portanto nos casos usuais ${ }^{27} \gamma_{c}=1,4 / 1,1=1,27$, o que equivale, pragmaticamente, a multiplicar o resultado obtido de resistência do testemunho por 1,1, ou seja, aumentá-lo em 10\%, uma vez que o testemunho representa melhor a resistência efetiva do concreto na obra, no entorno daquela região de extração, do que o corpo-de-prova moldado.

Para fins de verificação dos ELS, ou seja, deformações (flechas), fissuração e tensão de trabalho, deve ser adotado $\gamma_{c}=1$.

\section{DEFINIÇÕES E NOMENCLATURA}

$f_{c k} \rightarrow$ resistência característica ${ }^{28}$ do concreto à compressão, aos 28 dias de idade, referenciada a corpos-de-prova padrão amostrados na boca da betoneira e ensaiados com carregamento único, de curta duração ou "instantâneo" e monotônico, adotada como valor referencial pelo projetista estrutural que deseja (admite) que 95\% do volume de concreto do componente estrutural tenha resistência à compressão acima desse valor e, conseqüentemente, $5 \%$ do total de volume do lote em exame, pode ter resistência abaixo desse valor ${ }^{29}$, porém, preferencialmente não muito longe desse valor ${ }^{30}$. Portanto $f_{c k}$ é um valor hipotético ou de gabinete (imaginário, desejado, idealizado). É o valor utilizado pelo Projetista estrutural tanto como ponto de partida dos cálculos de dimensionamento como na análise de revisão do projeto do ponto de vista da segurança estrutural. 
Revista ALCONPAT, Volumen 1, Número 1, Enero-Abril 2011, Páginas 64 - 89

Também é o valor utilizado para fins de análise de durabilidade, quando necessário o estudo de vida útil de projeto ou vida útil residual;

$f_{c k, e f} \rightarrow$ resistência efetiva característica do concreto à compressão, aos 28 dias de idade, no componente estrutural, na estrutura construída. Trata-se de um valor impossível de ser conhecido pois dependeria de ensaiar à ruptura o próprio componente estrutural ou a estrutura (ensaio de carregamento único, de curta duraçãoo ${ }^{31}$ e monotônico). Admite-se, no entanto, que, na expressiva maioria das situações de obra, deve sempre ser menor que $\boldsymbol{f}_{\boldsymbol{c k}}$ devido a diferenças de geometria, cura, adensamento, segregação interna, variabilidade da resistência do concreto superior à de produção medida através de corpos-de-prova padrão, simplificação dos modelos de cálculo, etc. Trata-se de um valor que depende do próprio concreto e, principalmente, da qualidade e conformidade da execução ${ }^{32}$ em relação ao projeto;

$f_{c d} \rightarrow$ resistência de cálculo do concreto à compressão, aos 28 dias de idade, "disponível" ou "efetiva" no componente estrutural (também pressupondo ensaio de carregamento único, "instantâneo" e monotônico). Trata-se de um recurso matemático utilizado pelo projetista estrutural pois como é impossível conhecer $\boldsymbol{f}_{\boldsymbol{c}, \boldsymbol{e} \boldsymbol{e}}$ este adota $\boldsymbol{f}_{\boldsymbol{c} \boldsymbol{d}}$ como um valor provável de $f_{c k, e f}$ observando que esse valor sempre será inferior a $f_{c k}$, minorando-o (no Brasil), em geral com $\gamma_{\boldsymbol{c}}=1,4$, ou seja, $\boldsymbol{f}_{\boldsymbol{c} \boldsymbol{d}}=\boldsymbol{f}_{\boldsymbol{c} \boldsymbol{k}} / \boldsymbol{\gamma}_{\boldsymbol{c}}$. Trata-se também de um valor hipotético ou de gabinete (imaginário, desejado) ${ }^{33}$. Os projetistas adotam esse valor minorado desejando que a execução da estrutura esteja sob controle e atenda, no mínimo, à NBR 14931:2004;

$f_{c, j} \rightarrow$ resistência à compressão do concreto, à idade $j$, medida através de procedimentos padronizados de controle de recebimento em corpos-de-prova padrão retirados na "boca" da betoneira (ensaio de carregamento único, "instantâneo" e monotônico) conforme com o método de moldagem NBR 5738:2003. Moldagem e cura de corpos-deprova cilíndricos ou prismáticos de concreto, e devem ser sazonados, ensaiados e rompidos a $\boldsymbol{j}$ dias de idade, segundo a NBR 5739:2007. Concreto. Ensaio de compressão de corpos-de-prova cilíndricos, ensaiados em laboratórios credenciados e pertencentes à RBLE do INMETRO. Representa a resistência média potencial daquele volume definido e homogêneo de concreto bem misturado, ao sair da betoneira ${ }^{34}$, conhecido por valor do exemplar. É o primeiro valor realmente medido fisicamente da resistência à compressão do concreto e, em geral, o único. Cada betonada deve ser representada por um único valor de resistência à compressão numa certa idade, $\boldsymbol{f}_{\boldsymbol{c}, j .}$. Segundo a NBR 12655:2006, o valor representativo do exemplar deve ser o maior valor obtido entre os corpos-de-prova irmãos. Portanto cada unidade de produto, ou seja, cada betonada, tem um único valor de resistência à compressão numa certa idade, admitido como o potencial naquela idade, na boca da betoneira;

$f_{c k, e s t} \rightarrow$ resistência característica estimada à compressão do concreto, aos 28 dias de idade, obtida por procedimentos padronizados prescritos pela NBR 12655:2006 Concreto de Cimento Portland. Preparo, Controle e Recebimento. Procedimento. Admite-se que o concreto tenha sido bem produzido em canteiro ou em Central, neste caso em conformidade com a NBR 7212:1984. Especificação para a execução do concreto dosado em central. Especificação. A $\boldsymbol{f}_{\text {ck,est }}$ representa a resistência característica do concreto à compressão num determinado lote de concreto em exame ${ }^{35}$, a partir do conhecimento dos $f_{c, 28}$. Deve ser igual ou superior ao $f_{c k}$ previamente especificado pelo projetista da estrutura. Para o controle da resistência do concreto é necessário distinguir dois procedimentos distintos: o controle total que permite rastreabilidade, onde o concreto de cada betonada é controlado individualmente (100\%), e também é realizado o 
Revista ALCONPAT, Volumen 1, Número 1, Enero-Abril 2011, Páginas 64 - 89

mapeamento dos locais de lançamento do concreto na estrutura, e o controle parcial, onde o controle é feito sem que seja realizado o mapeamento dos locais de lançamento do concreto na estrutura, independentemente se a amostragem é total ou parcial;

$f_{c, e x t, j} \rightarrow$ resistência à compressão do concreto extraído, obtida a partir de testemunhos extraídos e ensaiados através de procedimentos padronizados ${ }^{36}$, obtida a uma idade $\boldsymbol{j}$ qualquer e, em geral, acima de 28 dias (ensaio de carregamento único, "instantâneo" e monotônico). É um segundo valor fisicamente medido e muito mais próximo de $f_{c k, e f}$ (ou seja, de $f_{c d}$ ) do que o $\boldsymbol{f}_{\boldsymbol{c k} \text {,est. }}$. Trata-se da resistência à compressão de uma porção íntegra e representativa do concreto de um componente estrutural. Considera-se que além das maiores variabilidades da resistência do concreto na estrutura, em princípio cobertas pelo $\gamma_{c}=\gamma_{c 1}$ - $\gamma_{c 2} \cdot \gamma_{c 3}=1,4$, também as operações de extração e ensaio, por melhor que sejam realizadas, introduzem efeitos deletérios no testemunho e reduzem sua resistência original. No mínimo, tem-se duas considerações: uma devida à redução do $\boldsymbol{f}_{\boldsymbol{c}, \boldsymbol{e x t}}$ em relação ao $f_{c, e f}$ e outra que $f_{c, e x t}$ é mais "próximo" de $f_{c, e f}$. Portanto requereria, no mínimo, dois coeficientes de "correção" para passar de $\boldsymbol{f}_{c, \text { ext }, j}$ a $\boldsymbol{f}_{c, j}$;

$\sigma_{c d} \rightarrow$ tensão de cálculo do concreto à compressão, aos 50 anos de idade, utilizada pelo projetista estrutural, admitindo uma situação hipotética e conservadora de que o carregamento máximo de projeto, nas condições dos estados limites últimos ELU, seria aplicado aos 28 dias de idade e mantido até 50 anos de idade. Trata-se de um valor hipotético e admitido como disponível no elemento estrutural, para fins de introdução da segurança no projeto da estrutura, $\sigma_{c d}=f_{c d} * \beta=f_{c k} / \gamma_{c} * \beta=f_{c d} * 0,85$. Do ponto de vista prático equivale à "tensão máxima admissível" do concreto. Para considerar os efeitos do crescimento da resistência com a idade combinado com as consequiências deletérias da ação da carga mantida e de longa duração ${ }^{37}$ é introduzido um coeficiente $\boldsymbol{\beta}$ que tem origem nos trabalhos de Rüsch ${ }^{38}$;

$\beta \rightarrow \quad$ coeficiente de minoração da resistência de projeto do concreto à compressão que leva em conta os efeitos deletérios da ação das cargas de longa duração combinado com o efeito benéfico de crescimento da resistência do concreto com o tempo. É resultado do produto de dois coeficientes ${ }^{39}: \boldsymbol{\beta}_{1}$ que depende da taxa de crescimento da resistência à compressão do concreto a partir da data de aplicação da carga e $\beta_{2}$ que depende da taxa de "perda de capacidade resistente por efeito da carga de longa duração" do material (concreto, aço, madeira) também chamado no Brasil de efeito Rüsch. No caso da NBR 6118:2007, o valor de $\boldsymbol{\beta}=0.85$ é referido a 28 dias de idade ${ }^{40}$, ou seja, admite-se que o crescimento da resistência à compressão do concreto a partir de 28 dias até 50 anos será de apenas $\boldsymbol{\beta}_{1}=1.16 \mathrm{e}$ o decréscimo da resistência à compressão do concreto devido à carga aplicada aos 28dias e mantida até 50anos, o chamado efeito Rüsch, será de $\boldsymbol{\beta}_{2}=$ 0.73 , cujo produto resulta $\beta=1.16 * 0.73=0.85$. Observar que se tratam de valores muito conservadores pois, na realidade o crescimento da resistência do concreto de 28 dias a 50 anos, sempre supera $16 \%$ e o decréscimo por efeito Rüsch, segundo o próprio Rüsch $^{41}$ seria de no máximo 0,75 ;

$\beta_{1} \rightarrow$ coeficiente de crescimento da resistência à compressão do concreto a partir de 28dias. Depende de cada caso, tipo de cimento, condições de exposição do componente estrutural, relação água/cimento, natureza dos agregados, etc. A NBR 6118:2004, a favor da segurança e de forma conservadora, admite que a partir de 28dias até 50anos, a resistência cresce apenas 1,16 . Na ampla maioria dos casos reais esse crescimento é muito superior a $16 \%$. No caso de não se dispor de resultados reais de crescimento da resistência do concreto da estrutura em análise, ou seja, resultados experimentais 
Revista ALCONPAT, Volumen 1, Número 1, Enero-Abril 2011, Páginas 64 - 89

representativos, pode-se adotar como uma previsão também conservadora, o modelo matemático sugerido pelo CEB-FIP Model Code $90^{42}$, e adotado pela NBR 6118, item 12.3.3, amplamente aceito na tecnologia do concreto no país:

$$
\frac{f_{c, j}}{f_{c, 28}}=e^{s *\left(1-\sqrt{\frac{28}{j}}\right)}
$$

onde $\boldsymbol{j}$ é a idade do concreto em dias.

\begin{tabular}{|c|c|r|c|c|}
\hline CPV ARI & $\mathrm{s}=0,20$ & $1,21 \rightarrow 50$ anos & $1,15 \rightarrow 1$ ano & 1,05 de 1ano a 50anos \\
\hline CP I / II & $\mathrm{s}=0,25$ & $1,28 \rightarrow 50$ anos & $1,20 \rightarrow 1$ ano & 1,07 de 1ano a 50anos \\
\hline & & $\begin{array}{r}1,45 \rightarrow \\
\text { CP III / IV }\end{array}$ & $\begin{array}{c}50 \text { ano } \\
\mathrm{s}\end{array}$ & \\
& $\mathrm{s}=0,38$ & $1,32 \rightarrow 1$ ano & 1,10 de 1ano a 50anos \\
\hline NBR 6118 & $\mathrm{s}=0,1545$ & $1,16 \rightarrow 50$ anos & $1,11 \rightarrow 1$ ano & 1,05 de 1ano a 50anos \\
\hline
\end{tabular}

$\beta_{2} \rightarrow \quad$ coeficiente de decréscimo da resistência à compressão do concreto por ação das cargas de longa duração ou efeito Rüsch. Segundo o próprio Rüsch, (vide Fig. 1), esse fenômeno se manifesta de forma "constante" e independente valendo as seguintes verdades:

$>$ independe do nível do $f_{c}$, ou seja, é igual para qualquer valor de $f_{c k}$;

$>$ o máximo coeficiente de "perda de capacidade resistente por efeito da carga de longa duração" é sempre o mesmo, ou seja, para $\boldsymbol{t}_{\infty}$ sempre vale 0.75 , qualquer que seja o $\boldsymbol{t}_{\boldsymbol{0}}$ de aplicação das cargas de longa duração;

o mecanismo de "perda de capacidade resistente por efeito da carga de longa duração" é sempre o mesmo qualquer que seja a data, to (idade), de aplicação da carga;

o coeficiente de "perda de capacidade resistente por efeito da carga de longa duração" é sempre referido, ou seja, sempre aplicado à resistência do concreto na idade (data) $\boldsymbol{t}_{\boldsymbol{0}}$ de aplicação da carga.

Conforme CEB-FIP Model Code 90, Bulletin d'information 213/214, May 93, renovado por fib(CEB-FIP) Model Code 2010, o modelo matemático que melhor representa o efeito deletério da ação das cargas de longa duração é:

$$
\frac{f_{c, s u s, j}}{f_{c, t_{0}}}=0,96-0,12 * \sqrt[4]{\ln \left\{72 *\left(j-t_{0}\right)\right\}}
$$

no qual:

$\boldsymbol{f}_{c, s u s, j}=$ resistência à compressão do concreto sob carga mantida, na idade $\boldsymbol{j}$ dias, em MPa;

$\boldsymbol{f}_{\boldsymbol{c}, \boldsymbol{t} \boldsymbol{t}}=$ resistência potencial à compressão do concreto na data (idade) to instantes antes de aplicação da carga de longa duração, em MPa;

$\boldsymbol{t}_{\boldsymbol{0}}=$ idade de aplicação da carga, em dias, considerada significativa ${ }^{43}$;

$\boldsymbol{j}=$ qualquer idade do concreto "a posteriori" de $\boldsymbol{t}_{\boldsymbol{0}}$, expressa em dias ou fração de dias

exemplos:

$\boldsymbol{t}_{0}=28$ dias $\rightarrow$ para 28dias $+1 \mathrm{~h} \rightarrow f_{c, 28 d+1 h}=0,84 \bullet f_{c, 28 d}$

P. Helene 
Revista ALCONPAT, Volumen 1, Número 1, Enero-Abril 2011, Páginas 64 - 89

$t_{0}=28 d i a s \rightarrow$ para 1 ano $\rightarrow f_{c, 1 a n o}=0,75 \bullet f_{c, 28 d}$

$\boldsymbol{t}_{\mathbf{0}}=\mathbf{2 8 d i a s} \rightarrow$ para 50 anos $\rightarrow f_{c, 50 a n o s}=0,73 \bullet f_{c, 28 d}$

$\boldsymbol{t}_{\mathbf{0}}=\mathbf{1 a n o}(C P V) \rightarrow$ para $1 \mathrm{ano}+1 \mathrm{~h} \rightarrow f_{c, 1 a n o+1 h}=0,84 \bullet f_{c, 1 a n o}=0,84 \bullet 1,15 \bullet f_{c, 28 d}=0,97 \bullet f_{c, 28 d}$

$\boldsymbol{t}_{\mathbf{0}}=\mathbf{l a n o}(C P I I I) \rightarrow$ para $1 \mathrm{ano}+1 \mathrm{~h} \rightarrow f_{c, 1 a n o+1 h}=0,84 \bullet f_{c, 1 a n o}=0,84 \bullet 1,32 \bullet f_{c, 28 d}=1,11 \bullet f_{c, 28 d}$

$t_{0}=1$ lano $(C P V) \rightarrow$ para 50 anos $\rightarrow f_{c, 50 a n o s}=0,73 \bullet f_{c, 1 a n o}=0,73 \bullet 1,15 \bullet f_{c, 28 d}=0,84 \bullet f_{c, 28 d}$

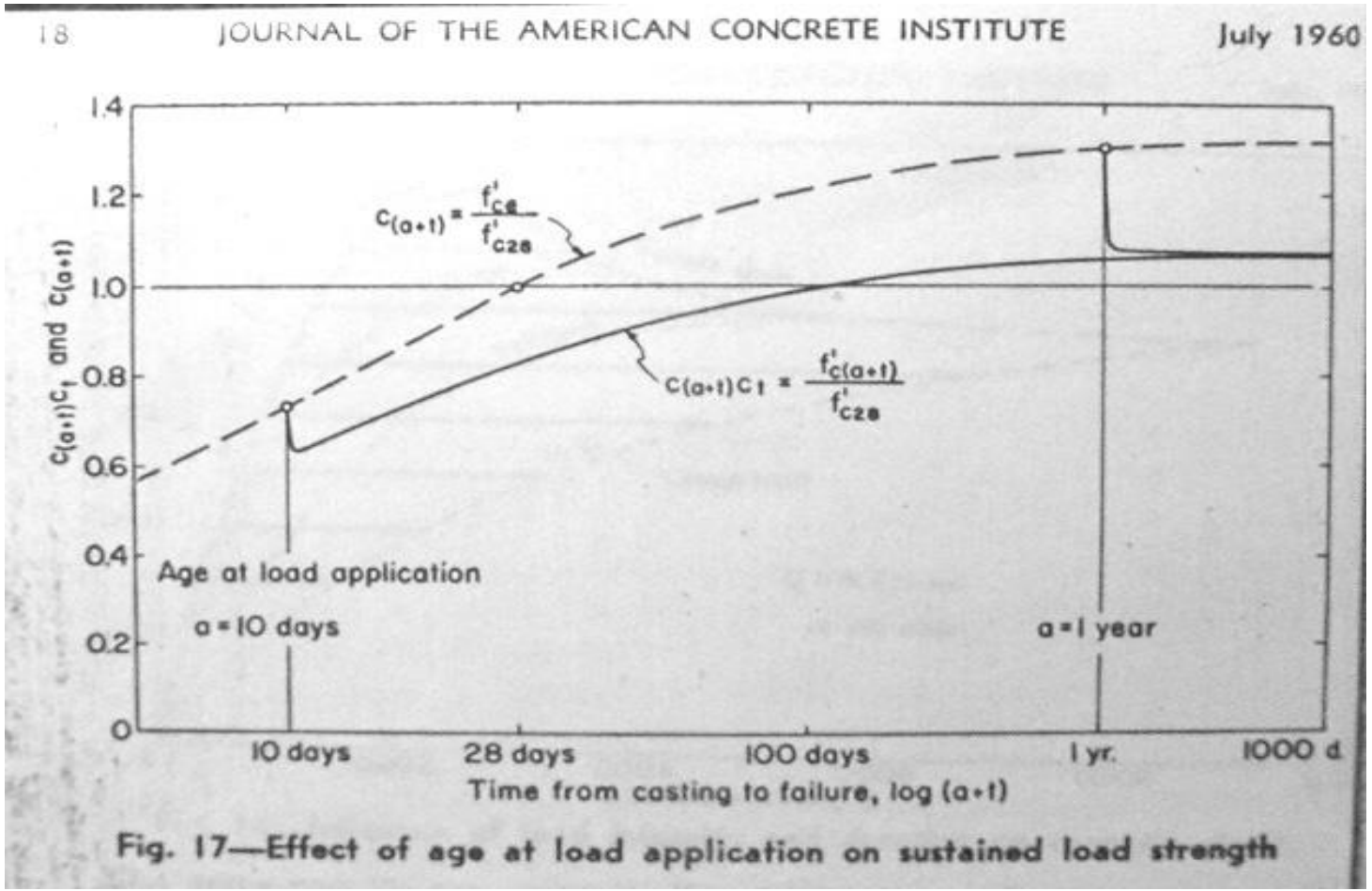

Figura 1. Reprodução (cópia) da expressiva representação da "perda de capacidade resistente por efeito da carga de longa duração" do concreto, segundo Rüsch ${ }^{41}$.

Resumindo pode-se afirmar que aos 50anos:

$\boldsymbol{\beta}_{2} \geq 0,73$ de $f_{c k} \rightarrow$ para carga aplicada a 28dias (talvez somente algumas lajes poderão sofrer o carregamento de projeto em 28dias) para qualquer cimento

$\boldsymbol{\beta}_{2} \geq 0,84$ de $\boldsymbol{f}_{\boldsymbol{c}} \rightarrow$ para carga aplicada a 1 ano (maioria dos pilares de edifícios) para qualquer cimento

ou seja, adotar 0,73 para efeito Rüsch é estar sempre do lado mais conservador, pois na maioria das vezes a situação real é de estar com cargas efetivas em idades superiores a 28dias e com concreto de cimentos que crescem muito mais que $16 \%$ a partir de 28 dias até 50 anos.

Por outro lado ao admitir que o concreto foi carregado significativamente aos 28dias, é possível calcular de quanto varia o efeito Rüsch (a "perda de capacidade resistente por efeito da carga de longa duração") de uma certa idade, por exemplo 1 ano, até os 50anos. Fazendo os cálculos

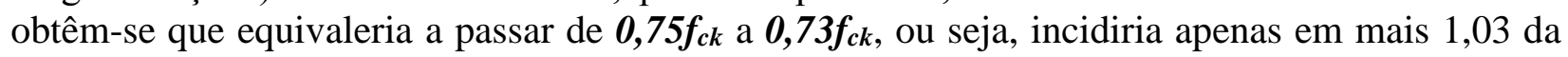
"perda de capacidade resistente por efeito da carga de longa duração" ocorrida até 1ano.

Portanto 92,6\% da "perda de capacidade resistente por efeito da carga de longa duração" se manifesta no primeiro ano e apenas $7,4 \%$ do total se manifesta de 1 ano a 50 anos, para estruturas carregadas a 28 dias. 
Revista ALCONPAT, Volumen 1, Número 1, Enero-Abril 2011, Páginas 64 - 89

\begin{tabular}{|c|c|c|c|c|}
\hline idade & moldagem & $\mathbf{2 8}$ dias & $\mathbf{1}$ ano & $\mathbf{5 0}$ anos \\
\hline idade & $\mathbf{0}$ & $\boldsymbol{t}_{0}$ & $\boldsymbol{j}_{1}$ & $\boldsymbol{j}_{2}$ \\
\hline$f_{c}$ relativa & $\mathbf{0}$ & $\mathbf{1 , 0 0}$ & $\mathbf{0 , 7 5}$ & $\mathbf{0 , 7 3}$ \\
\hline $\begin{array}{l}\text { "perda de } \\
\text { capacidade } \\
\text { resistente por } \\
\text { efeito da carga de } \\
\text { longa duração" \% }\end{array}$ & $\mathbf{0}$ & - & & $\mathbf{9 2 , 6}$ \\
\hline carga \% & & & & \\
\hline
\end{tabular}

\section{FATORES QUE AFETAM A RESISTENCIA IN SITU DO CONCRETO}

A resistência à compressão do concreto na estrutura é compreensivelmente menor que na boca da bica da betoneira devido aos seguintes fatores principais:

1. Segregação $\rightarrow$ nos elementos estruturais de grande altura $(>30 \mathrm{~cm})$ há uma tendência dos materiais mais leves do traço, o ar e a água, subir para as partes mais altas, reduzindo a resistência potencial do concreto no topo de pilares, por exemplo, ou na superfície de lajes e vigas (exsudação). Essa diferença é tanto maior quanto mais inadequado for o traço, o lançamento e o adensamento do concreto ou mesmo a coesão do concreto devido a uma dosagem inadequada ${ }^{44}$. Segundo $A C I 214.4 R-10$ o concreto do topo de pilares pode apresentar resistência $15 \%$ menor que aquela do terço inferior. Portanto poder-se-ia escrever que $f_{c, j}=\boldsymbol{k}_{\text {seg }} * f_{c, \text { ext }, j}$ onde $\boldsymbol{k}_{\boldsymbol{s e g}} \geq 1,0$;

2. Exsudação $\rightarrow$ as superfícies superiores de concretagem em pilares, vigas e lajes podem apresentar uma camada de exsudação que deve ser descartada por ocasião do ensaio de resistência à compressão, através de corte com disco de corte de pelo menos $2 \mathrm{~cm}$ do concreto superficial $^{45}$. Quando essa camada é significativa e não retirada da estrutura na retomada da concretagem em cabeças de pilar, pode ser responsável por maior fluência total daquele pilar. Portanto poder-se-ia escrever que $\boldsymbol{f}_{\boldsymbol{c}, j}=\boldsymbol{k}_{\boldsymbol{e x s}} * \boldsymbol{f}_{\boldsymbol{c}, \boldsymbol{e x t}, j}$ onde $\boldsymbol{k}_{\text {exs }} \geq 1,0$;

3. Adensamento $\rightarrow 1 \%$ a mais de ar aprisionado pode ser responsável por $7 \%$ a menos na resistência à compressão, segundo ACI 214.4R-10. Portanto comprovar a eficiência e homogeneidade do adensamento, por exemplo com ensaios esclerométricos, é importante para evitar julgamentos precipitados sobre a efetiva resistência potencial do concreto de origem. Observe-se que o coeficiente de minoração da resistência à compressão do concreto, $\gamma_{c}$, já prevê essa dispersão negativa e portanto há de ser buscada a resistência potencial desse concreto e não a menor existente num certo pilar. Esse é outro conceito muito importante. Portanto poder-se-ia escrever que $\boldsymbol{f}_{\boldsymbol{c}, \boldsymbol{j}}=\boldsymbol{k}_{\text {ade }} * \boldsymbol{f}_{\boldsymbol{c}, \boldsymbol{e x t}, \boldsymbol{j}}$ onde $\boldsymbol{k}_{\text {ade }} \geq 1,0$;

4. Cura $\rightarrow$ segundo o ACI 214.4R-10 uma cura deficiente pode reduzir em até $10 \%$ a resistência à compressão que o concreto de origem possuía, na boca da betoneira, principalmente nas regiões superficiais do componente estrutural. Portanto poder-se-ia escrever que $\boldsymbol{f}_{\boldsymbol{c}, j}=\boldsymbol{k}_{\boldsymbol{c u r}} * \boldsymbol{f}_{\boldsymbol{c}, \boldsymbol{e x t}, j}$ onde $\boldsymbol{k}_{\boldsymbol{c u r}} \geq 1,0$;

5. Calor de hidratação $\rightarrow$ segundo o ACI 214.4R-10 temperaturas elevadas devido ao calor de hidratação em peças massivas, podem reduzir em até $23 \%$ a resistência à compressão do concreto de origem, na boca da betoneira. Portanto poder-se-ia escrever que $f_{c, j}=\boldsymbol{k}_{c a l}$ * $\boldsymbol{f}_{\boldsymbol{c}, \boldsymbol{e x t}, j}$ onde $\boldsymbol{k}_{\boldsymbol{c} a l} \geq 1,0$

6. Microfissuração $\rightarrow$ carregamentos precoces, descimbramentos precoces, impactos a baixa idade, podem reduzir a resistência do concreto em até $11 \%$, segundo ACI $214.4 R$ 10. Portanto poder-se-ia escrever que $\boldsymbol{f}_{\boldsymbol{c}, \boldsymbol{j}}=\boldsymbol{k}_{\boldsymbol{m i c}} * \boldsymbol{f}_{\boldsymbol{c}, \boldsymbol{e x t}, \boldsymbol{j}}$ onde $\boldsymbol{k}_{\boldsymbol{m i c}} \geq 1,0$; 
Revista ALCONPAT, Volumen 1, Número 1, Enero-Abril 2011, Páginas 64 - 89

7. Direção de lançamento do concreto comparada com direção de extração do testemunho $\rightarrow$ segundo o ACI 214.4R-10, os testemunhos extraídos em direção ortogonal à direção de lançamento e adensamento do concreto (geralmente direção vertical igual à da gravidade) apresentam resistências à compressão inferiores $(0 \%$ a $12 \%)$ àquelas obtidas de testemunhos extraídos na mesma direção vertical ${ }^{46}$. Mais uma razão que explica o porquê da resistência do testemunho sempre ser inferior à do corpo-de-prova moldado que foi ensaiado na mesma direção de lançamento, ou seja, na vertical igual à direção de trabalho do concreto num pilar da estrutura. Portanto poder-se-ia escrever que $f_{c, j}=\boldsymbol{k}_{\text {dir }} * \boldsymbol{f}_{c, \boldsymbol{e x t}, j}$ onde $\boldsymbol{k}_{\text {dir }} \geq 1,0$;

8. Relação altura/diâmetro $\rightarrow$ o efeito da relação altura/diâmetro do testemunho é controverso na literatura, sendo que alguns pesquisadores consideram que os coeficientes dependem do nível de resistência do concreto. Para os casos de concretos e estruturas usuais considera-se adequados os coeficientes recomendados pela NBR 7680. Portanto poder-se-ia escrever que $\boldsymbol{f}_{\boldsymbol{c}, \boldsymbol{j}}=\boldsymbol{k}_{\boldsymbol{h} / \boldsymbol{d}} * \boldsymbol{f}_{\boldsymbol{c}, \boldsymbol{e x t}, \boldsymbol{j}}$ onde $\boldsymbol{k}_{\boldsymbol{h} / \boldsymbol{d}} \geq 0,8$

9. Diâmetro do testemunho $\rightarrow$ também aqui há controvérsias, pois o ideal seria extrair testemunhos com $15 \mathrm{~cm}$ de diâmetro e $30 \mathrm{~cm}$ de altura, porém as restrições geométricas e de bom senso recomendam extrair testemunhos de $2,5 \mathrm{~cm}$ de diâmetro por $5 \mathrm{~cm}$ de altura ${ }^{47}$. Uns entendem que as diferenças são desprezíveis enquanto outros recomendam que um estudo seja feito na obra, quando houver dúvidas substanciais (posição do ACI 214.4R10). Este pesquisador concorda com os primeiros, ou seja, considera que as diferenças introduzidas pela variação do diâmetro do testemunho são desprezíveis na grande maioria dos casos e não justifica estudos de correlação em obra que são complexos, caros e de difícil conclusão.

Diversos trabalhos buscaram quantificar a diferença total entre a variabilidade e a resistência à compressão do concreto numa produção rigorosa com a variabilidade (maior) e a resistência (menor) do concreto numa estrutura.

Conforme descrito anteriormente poder-se-ia utilizar um modelo do tipo:

$$
\boldsymbol{f}_{c, j}=\boldsymbol{k}_{\text {seg }} * \boldsymbol{k}_{\text {exs }} * \boldsymbol{k}_{\text {ade }} * \boldsymbol{k}_{\text {cur }} * \boldsymbol{k}_{\text {cal }} * \boldsymbol{k}_{\text {mic }} * \boldsymbol{k}_{\text {dir }} * \boldsymbol{k}_{\boldsymbol{h} / \boldsymbol{d}} * \boldsymbol{f}_{\boldsymbol{c}, \text { ext }, j}
$$

Podendo-se considerar esse produto de coeficientes $(k)$ como aproximadamente equivalente ao coeficiente parcial de minoração da resistência do concreto, $\gamma_{c 1}$ conforme descrito neste trabalho. Segundo Bartlett and MacGregor ${ }^{48}$ o coeficiente de variação do concreto numa estrutura bem realizada com controle rigoroso, deveria ser da ordem dos valores indicados na Tabela 1. Caso sejam superiores denotariam produção e execução deficientes, sendo muito difícil distinguir entre elas, ou seja, se foi a produção (Concreteira), a execução (Construtora) ou o controle (Laboratório) o maior responsável pela elevada variabilidade dos resultados.

Tabela 1. Coeficientes de variação da resistência à compressão do concreto numa estrutura.

\begin{tabular}{|c|c|c|c|}
\hline concreto & tipo de estrutura & um elemento & vários elementos \\
\hline mesma betonada & todas & $7 \%$ & $8 \%$ \\
\hline várias betonadas & concretada in loco & $12 \%$ & $13 \%$ \\
\hline várias betonadas & pré-moldada & $9 \%$ & $10 \%$ \\
\hline
\end{tabular}

No Brasil, Cremonini ${ }^{49}$, em sua excelente tese de doutorado pesquisou com propriedade e quantificou o coeficiente $\gamma_{c 1}$ conforme definido neste documento (pois alguns pesquisadores o chamam de $\gamma_{c 2}$, na verdade tanto faz pois $\gamma_{c}$ é um produto de coeficientes gama), encontrando, para o caso de construção de edifícios de vários pavimentos, com concreto produzido em 
Revista ALCONPAT, Volumen 1, Número 1, Enero-Abril 2011, Páginas 64 - 89

Centrais, caminhões-betoneira de $8 \mathrm{~m}^{3}$, e velocidades de concretagem de 1 laje por semana, com desvio padrão de produção $\leq 4 \mathrm{MPa}$, relação entre a resistência média à compressão de corpos-deprova moldados $\boldsymbol{f}_{\boldsymbol{c m}, \mathbf{2 8 d} \boldsymbol{d}}$ e as resistências médias obtidas diretamente do ensaio de testemunhos com relação $\mathrm{h} / \mathrm{d}=2$, de $f_{c m, 28}=1,24 * f_{c m, e x t, 28}$.

Portanto equivalente a $\gamma_{c 1}=1,24$, coerente com os coeficientes de minoração adotados universalmente. Por outro lado, ao comparar os valores característicos essa diferença subiu a

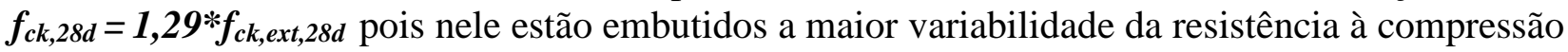
na estrutura comparada à variabilidade da resistência à compressão na boca da betoneira (produção).

Também no Brasil, Vieira Filho ${ }^{47}$, em sua excelente tese de doutorado pesquisou em profundidade a influência negativa das operações de ensaio (microfissuração) nos resultados de resistência de testemunhos comparativamente à resistência obtida de corpos-de-prova moldados e todos ensaiados na mesma idade. Na sua tese ficou demonstrado que em média, $f_{c m, 28 d}=\mathbf{1 , 0 7 *}$ $f_{c, \text { ext,28d }}$ o que significa que as operações de extração reduzem a resistência do concreto. Encontrou como limites, 1,09 para concretos de 20MPa e 1,04 para concretos de $70 \mathrm{MPa}$.

A todas essas fontes de variabilidade deve ser acrescida a variabilidade das operações de ensaio. Segundo o ACI 214.4R-10, o coeficiente de variação para um mesmo operador é de $\boldsymbol{v}_{\boldsymbol{e}}=3,2 \%$ e entre vários operadores pode chegar a $v_{e}=4,7 \%$. Isso significa que parte da variabilidade total é devida às operações de ensaio, desde que estas estejam sob controle.

Do ponto de vista estatístico $v_{c}^{2}=v^{2}{ }_{p}+v^{2} e_{e}$ onde $v_{c}$ é o coeficiente de variação total das operações de ensaio, produção e execução do concreto; $v_{p}$ é o coeficiente de variação da produção de concreto na Central mais a variabilidade decorrente dos procedimentos de execução da estrutura na obra, e, $v_{\boldsymbol{e}}$ é o coeficiente de variação das operações de ensaio.

$\mathrm{Na}$ Tabela 2, apresenta-se o intervalo provável, esperado de variação dos resultados para um mesmo laboratorista, mesma estrutura, mesmo lote, mesmo tipo de componente estrutural, com testemunhos extraídos em posições geométricas equivalentes, segundo ACI 214.4R-10.

Tabela 2. Intervalo provável, esperado de variação dos resultados para um mesmo laboratorista, mesma estrutura, mesmo lote, mesmo tipo de componente estrutural, com testemunhos extraídos em posições equivalentes.

\begin{tabular}{|c|c|}
\hline $\begin{array}{c}\text { número de testemunhos "irmãos" pertencentes à } \\
\text { mesma betonada }\end{array}$ & $\begin{array}{c}\text { intervalo com somente 5\% de chance de ser excedido } \\
\boldsymbol{f}_{\boldsymbol{c}, \text { ext, inf }} \leq \boldsymbol{f}_{\boldsymbol{c}, \boldsymbol{e x t}} \leq \boldsymbol{f}_{\boldsymbol{c}, \text { ext sup }}\end{array}$ \\
\hline 3 & $\pm 10,6 \%$ \\
\hline 4 & $\pm 11,6 \%$ \\
\hline 5 & $\pm 12,4 \%$ \\
\hline 6 & $\pm 12,9 \%$ \\
\hline 7 & $\pm 13,3 \%$ \\
\hline 8 & $\pm 13,7 \%$ \\
\hline 9 & $\pm 14,1 \%$ \\
\hline 10 & $\pm 14,3 \%$ \\
\hline
\end{tabular}

\section{RESISTÊNCIA DO CONCRETO OBTIDA DE TESTEMUNHOS $\boldsymbol{F}_{C, E X T, J}$}

Diante de tantas variáveis aleatórias e de difícil mensuração há necessidade de experiência e bom senso no estabelecimento do plano de amostragem e na análise dos resultados.

Como procedimento básico, decorrente das informações anteriores, poder-se-ia recomendar:

1. Como decorrência das definições e dos conceitos anteriormente expressos, no caso de resistência à compressão do concreto em componentes estruturais, é preciso, 
primeiramente, saber se os componentes estruturais sob análise foram moldados com o concreto de uma mesma betonada;

2. Se positivo o próximo esclarecimento é observar se há bicheiras, vazios, defeitos, reparos, ou seja, se há deficiências evidentes de má execução;

3. Na sequiência indagar e medir dimensões, prumo e excentricidade do pilar (e eventualmente de outros componentes estruturais em análise). Com estrutura bem executada é possível aceitar $\gamma_{c}$ menores pois há menos desconhecimentos;

4. Se necessário utilizar ensaio de dureza superficial (esclerometria), para confirmar homogeneidade do concreto desse pilar;

5. Com essas informações e desde que haja evidências que permita considerar que se trata de um componente estrutural bem executado com desvios dentro das tolerâncias da NBR 14931, deve-se aplicar o pacômetro para identificar a posição das armaduras longitudinais e estribos, buscando confirmar se estão de acordo com o projeto estrutural. Se necessário proceder a uma prospecção visual com escarificação superficial;

6. Uma vez constatada a coerência do componente estrutural (por exemplo pilar), escolher o diâmetro do testemunho de forma a não cortar armaduras e proceder à extração, preferencialmente no centro de uma das faces, na região do terço inferior, logo acima do fim da região de traspasse das armaduras. Preferencialmente o testemunho deve ter uma altura igual ao dobro do diâmetro mas devido às operações de ensaio e preparação dos topos e devido à necessidade de descartar as superfícies, é sempre conveniente extrair um testemunho com altura igual ao dobro do diâmetro mais $5 \mathrm{~cm}$;

7. O testemunho deve sair íntegro, sem fissuras, sem vazios nem corpos estranhos, com geratriz retilínea. Se houver problemas extrair cuidadosamente outro na mesma face e vertical desse pilar em análise, um pouco acima, espaçado, no mínimo de 1 (um) diâmetro do testemunho anterior. Basta 1 ou 2 testemunhos por pilar, no máximo ${ }^{51}$;

8. No laboratório de ensaio conferir geometria, esquadro e ortogonalidade, conferir interface testemunho com prensa, observar forma de ruptura e fragmentos na busca de eventuais "corpos estranhos". Se tudo estiver bem, considerar o resultado como aproveitável. Caso contrário, descartar;

9. Considerando somente os resultados "confiáveis", a resistência à compressão do concreto nesse pilar é o maior valor obtido dos testemunhos "irmãos". Comparando esse valor com o resultado da resistência do corpo-de-prova moldado (referidos a uma mesma idade $\boldsymbol{j}$ ), se houver uma discrepância de $\pm 30 \%$ repetir os ensaios, pois deve haver algum erro grosseiro num dos procedimentos, ou no de extração ou no de moldagem (controle), ou em ambos. Ou não repetir, mas estar seguro de como justificar tamanha discrepância ${ }^{52}$.

Os resultados analisados dessa forma devem ser organizados em uma tabela comparativa de $\boldsymbol{f}_{\boldsymbol{c}, 28 \mathrm{dias}}$ com $\boldsymbol{f}_{\boldsymbol{c}, \boldsymbol{e x t}, \boldsymbol{j i}}$ buscando encontrar o $\boldsymbol{f}_{\boldsymbol{c}, \boldsymbol{e x t}, \boldsymbol{j}}$ definitivo (adotado) conforme modelo mostrado na Tabela 3 .

Tabela 3. Resistência à compressão do concreto obtida de testemunhos, $f_{c, \text { ext, } j}$

\begin{tabular}{|c|c|c|c|c|}
\hline local & resistência & resistência & resistência extraído, & resistência à compressão do \\
pilar & moldado & extraído, $1^{\mathrm{a}}$ & $2^{\mathrm{a}}$ campanha \\
viga & $\mathrm{MPa}, f_{c, 28 d i a s}$ & $\begin{array}{c}\text { campanha } \\
\text { concreto, adotada, em MPa, }\end{array}$ & $f_{c, \text { ext, } j}$ \\
& & $\mathrm{MPa}, f_{c, \text { ext }, j 1}$ & $\mathrm{MPa}, f_{c, \text { ext,j2 }}$ & \\
\hline
\end{tabular}


Revista ALCONPAT, Volumen 1, Número 1, Enero-Abril 2011, Páginas 64 - 89

\section{CONVERSÃO DE “EXTRAÍDO” $F_{C, E X T, J}$ A “MOLDADO” $F_{C, J}$ NA IDADE $J$}

O valor obtido por conta de se tratar de testemunho extraído, ou seja, além de ser afetado negativamente pelas operações de extração (1,07 segundo Vieira Filho já citado), para as quais ainda não há fatores de ajuste/correção consensuados no Brasil, também são afetados pelas operações de execução, ou seja, deveria ser corrigido por dois ou mais fatores. Certas normas assim o fazem mas no Brasil essa correção, necessária e justa, infelizmente ainda não é considerada no país.

Por exemplo, segundo ACI 214.4R-10, a conversão de "extraído" $f_{c, e x t, j}$ a "moldado" $f_{c, j}$ deveria atender a:

$$
f_{c, j}=F_{l / d} \bullet F_{d i a} \bullet F_{m c} \bullet F_{d} \bullet f_{c, e x t, j}
$$

$\boldsymbol{F}_{l / d}=$ coeficiente de correção da relação altura / diâmetro $\leq 2$ (consensuado no Brasil $e$ constante da NBR 7680);

$\boldsymbol{F}_{\text {dia }}=$ coeficiente de correção devido ao diâmetro (pode variar de 0,98 a 1,06) (ainda não consensuado no Brasil);

$\boldsymbol{F}_{\boldsymbol{m} \boldsymbol{c}}=$ coeficiente de correção devido a condições de sazonamento do testemunho (pode variar de 0,96 a 1,09) (ainda não consensuado no Brasil);

$\boldsymbol{F}_{\boldsymbol{d}}=$ coeficiente de correção devido à danificação decorrente da extração (broqueamento) (= 1,06) (ainda não consensuado no Brasil).

Em outras palavras os americanos, através da norma ACI 214.4R-10, aumentam o valor obtido diretamente do testemunho de 1 a 1,23 vezes para poder comparar com o valor de projeto (referido ao moldado).

Deixando de lado o efeito deletério do broqueamento que infelizmente não é levado ainda em conta no Brasil, há outro importante efeito a considerar: os resultados de testemunhos são muito mais representativos e mais próximos do $\boldsymbol{f}_{\boldsymbol{c} k \text {,ef }}$ que os corpos-de-prova moldados. Por essa razão, é possível reduzir $\gamma_{c}$, por dispor-se de um resultado que abarca maior conhecimento dos "desconhecimentos", ou seja, uma vez que é melhor conhecido aquilo que foi executado, pois a amostra extraída vem dele (do executado).

Na prática significa majorar de algo o resultado do extraído. As normas existentes e consagradas divergem sobre essa "majoração" a saber:

1. o item 12.4.1 da NBR 6118:2007 $\rightarrow$ com base na teoria da segurança:

$f_{c, j}=1.1 \cdot f_{c, e x t, j}$

aceitando uma redução de $\gamma_{c}$ em nome da maior representatividade de $\boldsymbol{f}_{\boldsymbol{c} \text {,ext }}$ em relação a $\boldsymbol{f}_{\boldsymbol{c k}, \boldsymbol{e} \boldsymbol{f}}$

2. a NBR 6118:1978 (válida até 2003) permitia considerar :

$f_{c, j}=1.15 \cdot f_{c, e x t, j}$

aparentemente mais coerente e mais justo devido ao grande número de variáveis no sentido negativo, de redução da resistência do testemunho

3. o ACI 437:2003 Strength Evaluation of Existing Concrete Buildings no item 5.1.1 recomenda:

$f_{c, j}=1.18 \cdot f_{c, e x t, j}$

4. o ACI 318:2005 Building Code Requirements for Structural Concrete, nos itens 9.3 e 20.2, recomenda:

$f_{c, j}=1.21$ a $1.25 \cdot f_{c, e x t, j}$

5. a fib(CEB-FIP) bulletin n.2. v.2. July 1999. Structural Concrete. updating CEB/FIP Model Code 90, item 6.3 p.59 recomenda:

$f_{c, j}=1.11$ a $1.20 \cdot f_{c, e x t, j}$

6. o EUROCODE II. EN 1992. Dec. 2004. Design of Concrete Structures. General Rules for Buildings. Annex A item A.2.3 - EN 13791 Assesment of Concrete Compressive Strength in Structures or in Structural Elements. p. 200, recomenda para revisão da segurança: 
Revista ALCONPAT, Volumen 1, Número 1, Enero-Abril 2011, Páginas 64 - 89

1. estrutura bem executada $\rightarrow$ revisar a segurança adotando:

$\gamma_{s}=1.05$ (ao invés de 1.15 )

$\gamma_{c}=1.35$ (ao invés de 1.50 ) $\rightarrow \gamma_{c}=1.26$ (equivalente no Brasil)

2. a partir de testemunhos extraídos revisar adotando:

$f_{c, j}=1.18 \cdot f_{c, e x t, j}$

Resumindo para ser conservador e estar conforme com a NBR 6118 :2007 deve-se majorar em apenas $10 \%$. Para ser pragmático e coerente com as demais normas nacionais e internacionais poder-se-ia majorar de $11 \%$ a $25 \%$ a critério do consultor e sempre com "bom senso". Observe-se que 1,24 foi o valor obtido na tese de Cremonini, já citada.

Com essas informações recomenda-se organizar uma nova tabela considerando esses diferentes coeficientes de ajuste, conforme mostrada na Tabela 4.

Tabela 4. Conversão de "extraído" a " moldado" segundo diferente normas, na idade $j$

\begin{tabular}{|c|c|c|c|c|c|c|c|}
\hline Local pilar & $f_{c, \text { ext }, j}$ & NBR & NBR & ACI 437 \& & Model & ACI & $f_{c, j}$ \\
viga & $\mathrm{MPa}$ & $6118: 2007$ & $6118: 2002$ & EUROCODE II & Code 90 & $318: 2005$ & adotado \\
& & 1,1 & 1,15 & 1,18 & 1,20 & 1,25 & $\mathrm{MPa}$ \\
\hline
\end{tabular}

Com muito bom senso e levando em consideração os aspectos de porosidade, imperfeições durante o processo de extração, qualidade dos topos (retificação) e planeidade do prato da prensa, importância do elemento estrutural (pilar ou laje), e outras, escolher um dos valores como o valor mais correto a ser adotado como $f_{c, j}$.

Atualmente no Brasil, por questões normativas, convém adotar o valor sugerido pela $N B R$ 6118:2007 e, somente em casos especiais, outro valor maior, por exemplo 1,15 da antiga $N B R$ 6118:1978, que foi válida até 2003. De qualquer forma adotar 1,15 ainda significa estar declaradamente a favor da segurança, penalizando a verdadeira resistência do concreto.

\section{CONVERSÃO de $\boldsymbol{F}_{C, J}$ A $\boldsymbol{F}_{C K, E S T}$ PARA 28DIAS}

Em primeiro lugar deve-se admitir que o $\boldsymbol{f}_{\boldsymbol{c}, \boldsymbol{e x t}, j}$ e o $\boldsymbol{f}_{\boldsymbol{c}, \boldsymbol{j}}$ se referem a mesmo lote, mesma betonada, ou seja, representam a resistência potencial do concreto daquela betonada (unidade de produto) e portanto podem ser admitidos como o $\boldsymbol{f}_{\boldsymbol{c k}, \boldsymbol{e s t}, j}$ daquele elemento estrutural, ou seja, resistência potencial característica estimada daquele concreto à compressão.

É a resistência que mais se aproxima daquela resistência que tinha a betonada que lhe deu origem, referida à idade $\boldsymbol{j}$.

Na seqüência para obter o $f_{\text {ck,est }}$ a 28 dias, deve ser considerado dois cenários: o concreto extraído está sob carga de longa duração que foi aplicada aos 28dias, ou, não foi ainda carregado, significativamente, ou seja, não está sob cargas de longa duração.

\section{$1^{\circ}$ cenário: o concreto extraído está sob carga de longa duração aplicada desde os 28dias}

$>$ Neste caso, não há necessidade de aplicar coeficientes para retroagir as resistências a 28dias pois se tratam de testemunhos extraídos de elementos sob carga, conforme Fig. 2;

$>$ Só teria sentido retroagir se fossem corpos-de-prova moldados e conservados em câmara úmida ou tanque de água com temperatura controlada porém sem carga.

$>$ A resistência atual sob carga, ou seja, já afetada, já diminuída, pelo efeito Rüsch é a obtida e constante da última coluna da Tabela 4. Na realidade, para efeito de segurança, essa resistência deveria ser comparada à resistência teórica que teria o modelo de segurança da NBR 6118:2003, ou seja, o produto dos $\boldsymbol{\beta}_{\boldsymbol{s}}$, o que equivale, neste exemplo de um ano de idade, a $\beta_{1}=1,11$ e $\beta_{2}=0,75$ e portanto $\beta=0,83$. Em outras palavras, sempre que $f_{c, j} \geq 0,83 \bullet f_{c k}$, o concreto poderia ser aceito ou considerado conforme;

$>$ Para revisar a segurança basta considerar que desta data em diante, por exemplo, de

Análise da resistência à compressão do concreto em estruturas acabadas com vistas... 
Revista ALCONPAT, Volumen 1, Número 1, Enero-Abril 2011, Páginas 64 - 89

1 ano, até 50anos, a resistência ainda vai $\operatorname{crescer}\left(\boldsymbol{\beta}_{1}\right)$ de 1,05 a 1,10 (depende do cimento utilizado) em relação ao valor atual $\left(f_{c k, l a n o}\right)$ e o efeito Rüsch $\left(\beta_{2}\right)$ poderá incidir apenas mais $3 \%$ ou seja 1,03 .

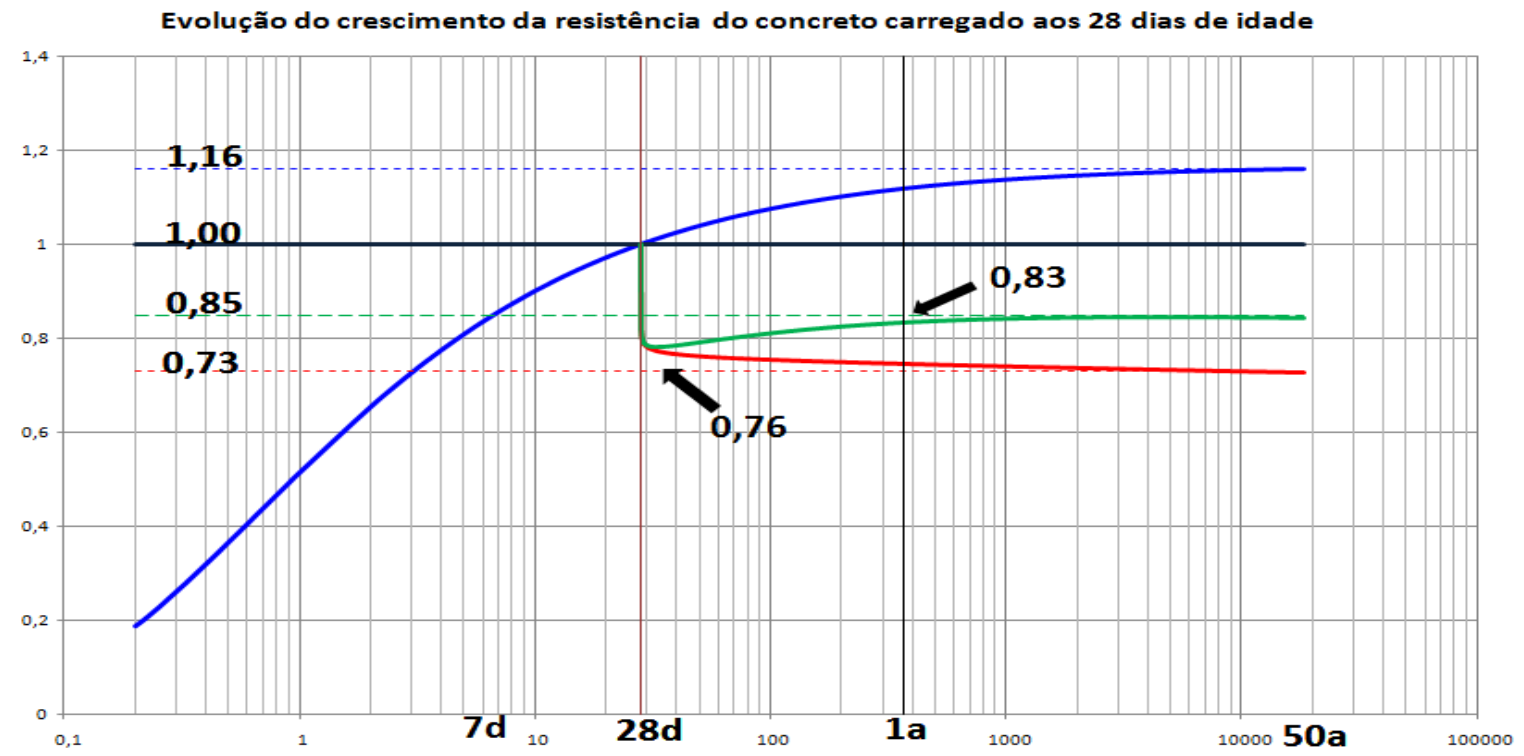

Figura 2. Evolução da resistência à compressão do concreto sob carga desde os 28dias.

Pragmaticamente, e a favor da segurança, significa adotar a resistência medida atual na idade de 1 ano $f_{c, j}$ como $f_{c k, e s t}$ a 28dias, ou seja $f_{c k, e s t}=f_{c, j}$ que neste exemplo seria $f_{c, 1 a}$.

$2^{\circ}$ cenário: o concreto extraído ainda não foi carregado e sua resistência cresceu "livre"

$>\mathrm{O} A C I 318$ e o ACI 214.4R-10, nestes casos, também adotam a resistência atual como a resistência de projeto. O EUROCODE II e outras normas não são claras nesse critério, mas geralmente nada comentam sobre a necessidade de retroagir a resistência a 28dias;

$>$ Como sugestão, neste caso, retroagindo a resistência atual para os 28dias obter-se-ia a resistência provável e estimada $\boldsymbol{f}_{\text {ck,est }}$ a 28 dias. No caso de 1 ano corresponderia a dividir o valor atual medido por 1,11 segundo o modelo de segurança da NBR 6118;

- Na seqüencia seria necessário aplicar o efeito Rüsch a partir da data de aplicação efetiva da carga, exemplificada neste caso como 1ano. Assim procedendo os coeficientes efetivos $\beta_{2}$, a serem utilizados para prever as resistências a 50anos sob carga constante aplicada a 1 ano seriam de $0,84 f_{c k, 28 d}$ a $0,96 f_{c k, 28 d}$ segundo o tipo de cimento, conforme Fig. 3; 
Revista ALCONPAT, Volumen 1, Número 1, Enero-Abril 2011, Páginas 64 - 89

Evolução do crescimento da resistência do concreto carregado a 1 ano de idade

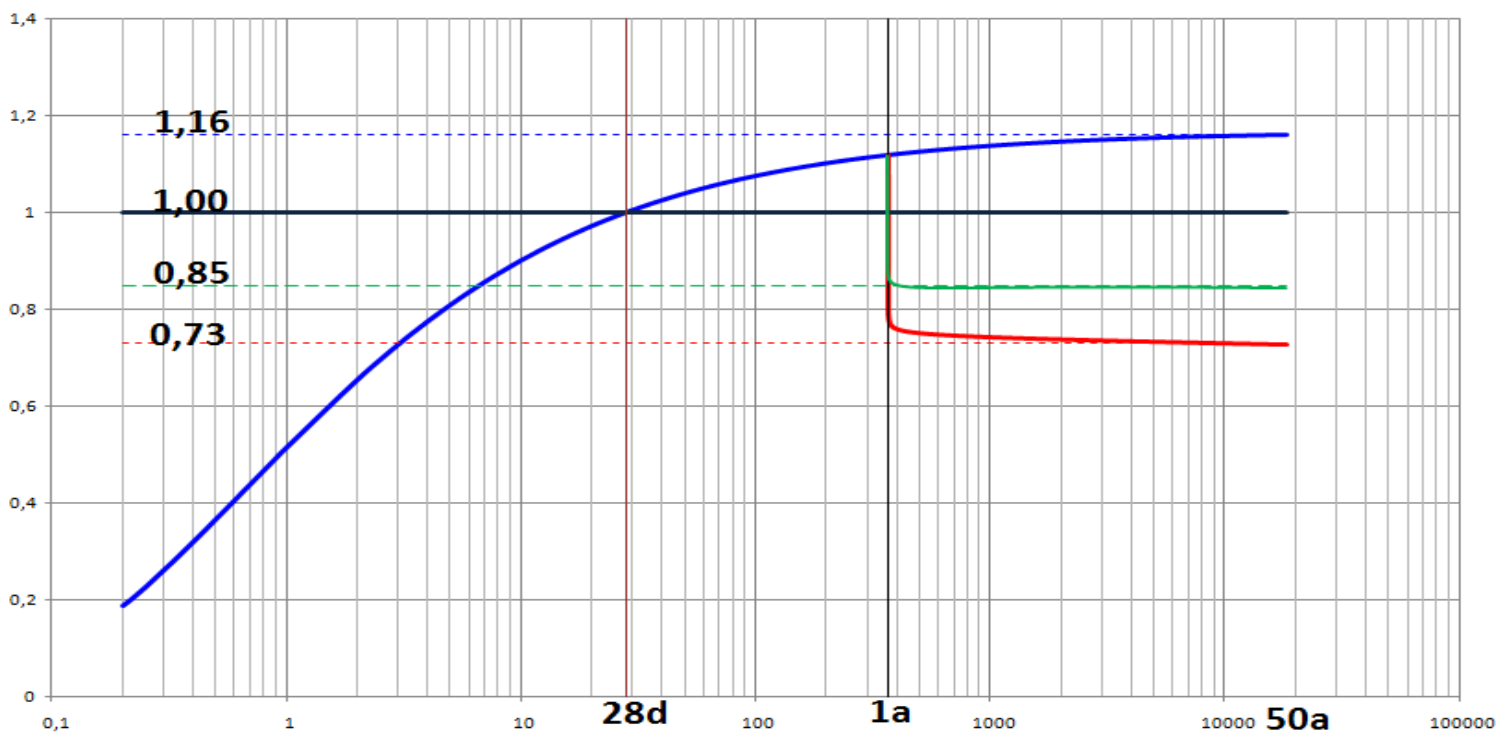

Figura 3. Evolução da resistência à compressão do concreto somente carregado a um ano de idade.

Por razões conservadoras o coeficiente $\boldsymbol{\beta}_{1}$ adotado na $N B R 6118$ é de apenas 1,16 , o que acarretaria neste exemplo a obter $\sigma_{c d}$ a 50 anos igual a $0,85 \bullet f_{c d}$ qualquer que seja o cimento utilizado, porém com uma grande vantagem de sempre estar acima de 0,85 , o que não ocorre com carregamentos a idades mais jovens;

$>$ Concluindo, neste caso, do ponto de vista prático, e a favor da segurança, significa adotar

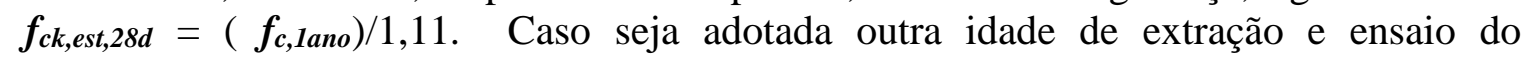
testemunho, então deve-se dividir a resistência atual pelo coeficiente $\boldsymbol{\beta}_{\boldsymbol{1}}$ da curva de crescimento da NBR 6118:2007.

Observa-se que a segurança estrutural adotada pela $N B R$ 6118, admite que a resistência do concreto cresce apenas $16 \%$ de 28 dias a 50 anos. Na realidade cresce muito mais e os concretos com cimentos CP III e CP IV terão reserva de segurança muito superior ao valor de norma em qualquer idade acima de 28dias e sem dúvida a 50anos.

\section{CONVERSÃO DE $\boldsymbol{F}_{C K, E S T}$ A $\boldsymbol{F}_{C K}$ PARA REVISÃO DE PROJETO}

O resultado apresentado na Tabela 4, não é aquele que deve ser utilizado na revisão de cálculo da estrutura pois são valores "quebrados" limitados por uma análise puramente matemática.

Do ponto de vista da engenharia de concreto as classes de concreto estão numa escala de $5 \mathrm{MPa}$, ou seja C20, C25, C30 e assim por diante até C50, conforme NBR 8953:2009. Concreto para fins estruturais. Classificação por grupos de resistência. Classificação, não tendo sentido físico nem no âmbito da engenharia de concreto considerar precisões de decimal ou valores intermediários entre as classes já consagradas e normalizadas.

Fazer este arredondamento é perfeitamente compatível com o desconhecimento das diversas variáveis envolvidas, todas no sentido de reduzir a resistência efetiva, desconsideradas nos cálculos e coeficientes anteriores.

Desta forma recomenda-se, com segurança e de forma conservadora, que os cálculos estruturais sejam revisados adotando-se os valores de $f_{c k}$ indicados na Tabela 5, e que as tensões de cálculo no concreto sejam obtidas a partir da fórmula clássica recomendada pela NBR 6118:2007, a saber: 
Revista ALCONPAT, Volumen 1, Número 1, Enero-Abril 2011, Páginas 64 - 89

$$
\sigma_{c d}=\frac{f_{c k} * 0.85}{\gamma_{c}}=\frac{0.85}{1.4} * f_{c k}
$$

Resultando, como exemplo, resistência à compressão para os pilares de $\boldsymbol{f}_{\boldsymbol{c}} \geq \mathbf{5 0 M P a}$ a 28 dias e tensão de cálculo do concreto disponível na peça para fins de dimensionamento no ELU, igual a $\sigma_{c d}=30,3 \mathrm{MPa}\left(\equiv f_{c k, e f}\right)$. Nos casos de $f_{c k} \geq 40 \mathrm{MPa}$, as tensões de cálculo deveriam ser $\sigma_{c \boldsymbol{c}}=$ 24,3MPa $\left(\equiv f_{c k, e f}\right)$.

Tabela 5. Resistência Característica do Concreto à

Compressão $f_{c k}$ para fins de revisão de Projeto (NBR 5983)

\begin{tabular}{|c|c|c|}
\hline $\begin{array}{l}\text { Local } \\
\text { pilar } \\
\text { viga }\end{array}$ & $\begin{array}{c}\text { resistência característica do concreto à } \\
\text { compressão admitindo pilares sem carga } \\
\mathrm{MPa}, f_{c k}\end{array}$ & $\begin{array}{c}\text { resistência característica do concreto } \\
\text { à compressão admitindo pilares em } \\
\text { carga } \\
\mathrm{MPa}, f_{c k}\end{array}$ \\
\hline $\mathrm{P}$ & C20 & C20 \\
\hline V & $\mathrm{C} 25$ & $\mathrm{C} 25$ \\
\hline $\mathrm{P}$ & C30 & C30 \\
\hline V & C35 & C35 \\
\hline $\mathrm{P}$ & C40 & C40 \\
\hline $\mathrm{P}$ & C45 & C45 \\
\hline $\mathrm{P}$ & C50 & C50 \\
\hline
\end{tabular}

\section{CONSIDERAÇOES FINAIS}

Encerrando, reitera-se que para fins de revisão do Projeto Estrutural deve ser adotado um novo $\boldsymbol{f}_{\boldsymbol{c k}}$ e não um $\boldsymbol{f}_{\text {ck,est }}$.

Nos casos gerais recomenda-se adotar os $\boldsymbol{f}_{\boldsymbol{c}}$ estabelecidos na NBR 8953:2009. Concreto para fins estruturais. Classificação por grupos de resistência. Classificação, ou seja: C20, C25, C30, C35, C40, C45, C50, C55, C60, C70, C80, C90 ou C100.

Portanto a partir do $f_{c k, e s t}$ adotar um $\boldsymbol{f}_{\text {ck }}$ de acordo com o seguinte critério pragmático:

Nos concretos C20 a C60, sempre fazer aproximação ao valor mais próximo tanto para cima como para baixo, ou seja:

$$
\begin{aligned}
& f_{c k, e s t}=37,4 \mathrm{MPa} \rightarrow \text { considerar } f_{c k}=\mathrm{C} 35 \\
& f_{c k, e s t}=44,1 \mathrm{MPa} \rightarrow \text { considerar } f_{c k}=\mathrm{C} 45 \text { e assim por diante. }
\end{aligned}
$$

Nos concretos C60 a C100, sempre fazer aproximação ao valor mais próximo tanto para cima como para baixo, ou seja:

$$
\begin{aligned}
& f_{c k, e s t}=64,7 \mathrm{MPa} \rightarrow \text { considerar } f_{c k}=\mathrm{C} 60 \\
& f_{c k, e s t}=87,5 \mathrm{MPa} \rightarrow \text { considerar } \boldsymbol{f}_{\boldsymbol{c k}}=\mathrm{C} 90 \text { e assim por diante. }
\end{aligned}
$$

"Portanto utilizar os mesmos modelos e programas como se os resultados fossem obtidos de corpos-de-prova moldados ensaiados em condições padronizadas a 28dias”, ou seja:

$$
\sigma_{c d}=\frac{f_{c k}}{\gamma_{c}} * 0.85
$$


Revista ALCONPAT, Volumen 1, Número 1, Enero-Abril 2011, Páginas 64 - 89

Conforme demonstrado, para fins de estimativa/cálculo de $f_{c k}$ a 28 dias de idade, a partir de corpos-de-prova rompidos a qualquer idade ou de testemunhos extraídos a qualquer idade, superior a 28dias, levando em conta o método de introdução da segurança no projeto das estruturas de concreto no Brasil (NBR 6118:2007), e apoiando-se nos conceitos de "perda de capacidade resistente por efeito da carga de longa duração" formulados por Rüsch em 1960, observa-se que o procedimento sempre comportará, três passos principais:

$1^{\circ}$ Corrigir o $f_{c, e x t, j}$ a moldado, ou seja $f_{c, j}$;

$2^{\circ}$ Obter o $f_{c k, e s t}$ (28dias) a partir do $f_{c, j}$ que na maioria dos casos pode ser o próprio valor obtido a $\boldsymbol{j}$ dias de idade (quando sob carga), ou o valor a $\boldsymbol{j}$ dias dividido pelo $\boldsymbol{\beta}_{\boldsymbol{l}}$ de crescimento da NBR 6118 (quando não está sob carga);

$3^{\circ}$ A partir dos $f_{\text {ck,est }}$ adotar pragmática e com bom senso, um $\boldsymbol{f}_{\boldsymbol{c k}}$ de acordo com a classificação dos concretos segundo a NBR 8953:2009. Concreto para fins estruturais. Classificação por grupos de resistência.

\section{REFERÊENIAS}

${ }^{1}$ A normalização americana para estruturas de edificações, ACI 318, adota $10 \%$ como o quantil inferior da distribuição admitida normal, das resistências à compressão do concreto. No caso de pavimentos de concreto adota quantil de 20\%. Brasil e EUROCODE adotam apenas 5\% de defeituosos. Observe-se que os americanos indicam por $f_{c}^{\prime}$ enquanto na Europa e Brasil usa-se a notação $f_{c k}$, porém ambos têm conceitos equivalentes em términos estatísticos, mas notação própria.

${ }^{2} \mathrm{O}$ volume de concreto de um caminhão betoneira usual, de $8 \mathrm{~m}^{3}$, pode ser suficiente para concretar 10 (dez) ou mais pilares de um edifício convencional. Portanto mesmo que apenas uma "betonada" esteja com resistência abaixo de $f_{c k}$, as consequiências podem ser desastrosas.

${ }^{3}$ Laniková, I.; Stepánek, Petr et al. Fully Probabilistic Design. The Way for Optimising of Concrete Structures. In: Proceedings of Conference 14. Betonárské dny 2007. CBS Servis, 2007, s. 421-426, (in Czech). Análise feita para ELS (SLS) e ELU (ULS).

${ }^{4}$ Observe-se que neste artigo de discussão técnica não está sendo considerada a questão comercial, ou seja, é possível em certas circunstâncias aceitar um concreto com resistência à compressão de 0,9 do $f_{c k}$ sem necessidade de reforço. Por outro lado, comercialmente, esse concreto pode ser penalizado pois o pedido / contrato de fornecimento foi de $f_{c k}$ e não $0,9 * f_{c k}$

${ }^{5}$ José Calavera Ruiz. La Influencia de lãs Variaciones Resistentes de los Materiales y de las Variaciones Dimensionales de las Piezas de Hormigón Armado sobre su Capacidad Resistente. Madrid, Instituto Eduardo Torroja, Monografia n. 324, Febrero 1975. 142p.

${ }^{6}$ Alfonso Juan Villanueva Gaspar. Influencia de las Variaciones Dimensionales e de Calidad de los Materiales en la Seguridad de Piezas de Hormigón Pretensado Trabajando a Flexión. Madri, Instituto Eduardo Torroja, Monografía n. 361, Septiembre 1980. 146p.

${ }^{7}$ Nos casos triviais, na chegada do caminhão betoneira, após bem misturar o concreto do balão no canteiro, deve ser retirada uma pequena porção de concreto para ensaios de consistência do concreto fresco. Estando dentro dos limites o início da descarga do concreto para a obra é autorizado. A retirada de uma porção de concreto para representar a resistência à compressão do concreto daquele balão, chamado na NBR 12655 de resistência do exemplar, por norma, deve ser realizada com retirada de uma porção pertencente ao volume do terço médio do balão. Este pesquisador recomenda retirar do último terço. Do ponto de vista físico ou de engenharia de concreto, tanto faz. Do ponto de vista matemático o terço central é mais representativo, mas do 
ponto de vista do risco de erro humano, retirar do terço final significa impedir até esse final que seja lançada água em excesso no balão, ou seja, reduz psicologicamente o risco de haver distorção significativa no traço e qualidade do concreto em um volume grande.

${ }^{8}$ NBRNM 067:1998 Concreto. Determinação da consistência pelo abatimento do tronco de cone. Método de Ensaio.

${ }^{9} \mathrm{Em}$ casos especiais de concreto produzido em obra, no canteiro, cabe aplicar as recomendações da NBR 5750 Amostragem de concreto fresco produzido por betoneiras estacionárias. Método de ensaio.

${ }^{10}$ A RBLE Rede Brasileira de Laboratórios de Ensaios é um conjunto de laboratórios credenciados pelo INMETRO segundo os requisitos da norma NBR ISO/IEC 17025 e congrega competências técnicas e capacitações vinculadas a indústrias, universidades e institutos tecnológicos, habilitados para a realização de serviços de ensaios. O credenciamento estabelece um mecanismo para evidenciar que os laboratórios se utilizam de um sistema da qualidade, que possuem competência técnica para realizar serviços de ensaios e assegurar a capacidade em obter resultados de acordo com métodos e técnicas reconhecidos nacional e internacionalmente. Os laboratórios da RBLE são utilizados para a realização de ensaios e testes de funcionamento e desempenho em produtos que possuem certificação compulsória ou voluntária. A rastreabilidade das medições é garantida através das calibrações dos padrões nos laboratórios da RBC Rede Brasileira de Calibração ou diretamente nos laboratórios do INMETRO.

${ }^{11}$ American Concrete Institute. ACI 214 Recommended practice for evaluation of compression test results of field concrete. Manual of Concrete Practice. Detroit, v.1, 2008

${ }^{12}$ American Concrete Institute. ACI 214.4R-10 Guide for obtaining cores and interpreting compressive strength results. ACI, June 2010.

${ }^{13}$ J. D. McIntosh. Concrete and statistics. London, CR Books, 1963

${ }^{14}$ Stanton Walker. Application of theory of probability to design of concrete for strenght specifications. Rock Products, v. 47, n.3, p. 70-4, mar. 1944

${ }^{15}$ F. N. Sparkes. The control of concrete quality: a review of the present position. In: Andrew, R. P., ed. Mix Design and Quality Control of Concrete: proceedings of a symposium. London, CCA, 1954, p.211-27

${ }^{16}$ Comite Euro-International du Béton. CEB-FIP Model Code 1990. Design Code. London, Thomas Telford, 1993

${ }^{17}$ Alvaro García Meseguer. Control de la Calidad. In: Colloque Européen sur le Contrôle de la Qualité dans la Construction, primer. Madrid, 1976. Compterendus, European Organizaton for Quality Control EOQC, 1976, p. 361-3

${ }^{18}$ Péricles Brasiliense Fusco. A influência da variabilidade da resistência do cimento na variabilidade da resistência do concreto. In: Seminário sobre Controle da Resistência do Concreto. São Paulo, 1979, Anais. IBRACON

${ }^{19}$ A ex-norma NBR 11562:1990. Fabricação e Transporte de Concreto para Estruturas de Centrais Nucleoelétricas (baseada num antiga recomendação do Bureau of Reclamation,USA), já considerada obsoleta pela ABNT, e portanto descartada, estabelecia que nenhum resultado de resistência à compressão dentro de um mesmo caminhão betoneira (mesma betonada) poderia diferir $\pm 7,5 \% \bullet f_{c m}$ (ou seja, nenhum resultado dentro da mesma betoneira pode diferir de mais ou menos $7,5 \%$ da resistência média dessa betonada). Em outras palavras isso equivale a dizer que o coeficiente de variação total das resistências dentro de uma betonada é sempre muito pequeno, ou seja, sempre menor que $v_{c}<2,5 \%$. Por essa razão desprezível diante de outras variáveis muito mais importantes.

${ }^{20} \mathrm{O}$ furo deixado pelo testemunho danifica o elemento estrutural e reduz muito sua capacidade portante. Por exemplo, um testemunho de diâmetro $10 \mathrm{~cm}$ com altura de $20 \mathrm{~cm}$, deixa um furo de 
$12 \mathrm{~cm} \times 22 \mathrm{~cm}$, no mínimo, que representa no caso de um pilar de secção quadrada de lado $40 \mathrm{~cm}$, mais de $16 \%$ de redução da secção resistente de concreto. Por essa e outras razões este pesquisador recomenda extrair o menor número possível de testemunhos e que estes sejam de pequenas dimensões e que nunca cortem armaduras.

${ }^{21}$ Paulo Helene. Concreto Endurecido. Avaliação da Dureza Superficial pelo Esclerômetro de Reflexão. São Paulo. Anais: II Simpósio sobre Normalização de Cimento, Concreto e Agregados. ABNT, CB-18 Comitê Brasileiro de Cimento, Concreto e Agregados, Nov. 1982. $28 \mathrm{p}$.

${ }^{22} \mathrm{Em}$ certas situações especiais, nas quais a densidade de armadura é muito grande e não há espaçamento livre entre barras longitudinais que permita a extração de testemunhos com esse diâmetro recomendável, é possível e seguro extrair mini-testemunhos ( $\square 25 \mathrm{mmx} 50 \mathrm{~mm})$, tomando-se os cuidados recomendados na tese de doutoramento de José Orlando Vieira Filho: Avaliação da Resistência à Compressão do Concreto através de Testemunhos Extraídos: Contribuição à Estimativa do Coeficiente de Correção devido aos Efeitos do Broqueamento. 2007, principalmente o relativo ao aumento do número de testemunhos por exemplar devido à maior variabilidade dos resultados. De qualquer modo extrair mini-testemunhos, sempre é mais seguro pois danifica menos a estrutura e nunca aumenta a resistência potencial do concreto. Se bem extraído, ensaiado e analisado, vai se aproximar da resistência efetiva e potencial a igual que qualquer outro testemunho.

${ }^{23}$ Paulo Helene. Avaliação da Resistência à Compressão de Estruturas Através de Testemunhos Cilíndricos de Concreto. São Paulo. São Paulo. Anais: I Simpósio sobre Normalização de Cimento, Concreto e Agregados. ABNT, CB-18 Comitê Brasileiro de Cimento, Concreto e Agregados, Out. 1980. 33p.

${ }^{24}$ Pedaços de madeira, agregados frágeis ou torrões de argila, pedaços de armadura, papel de jornal ou de saco de aglomerante, isopor, pó de serragem, casca de banana ou outras frutas, etc.

${ }^{25}$ ABNT NBR 15575-1:2010 Edifícios habitacionais de até cinco pavimentos. Desempenho Parte 1: Requisitos gerais

ABNT NBR 15575-2:2010 Edifícios habitacionais de até cinco pavimentos. Desempenho. Parte 2: Requisitos para os sistemas estruturais

ABNT NBR 15575-3:2010 Edifícios habitacionais de até cinco pavimentos. Desempenho. Parte 3: Requisitos para os sistemas de pisos internos

ABNT NBR 15575-4:2010 Edifícios habitacionais de até cinco pavimentos. Desempenh. Parte 4: Sistemas de vedações verticais externas e internas

ABNT NBR 15575-5:2010 Edifícios habitacionais de até cinco pavimentos. Desempenho. Parte 5: Requisitos para sistemas de coberturas

ABNT NBR 15575-6:2010 Edifícios habitacionais de até cinco pavimentos. Desempenho. Parte 6: Sistemas hidrossanitários

${ }^{26}$ NBR 7584:1995. Concreto endurecido. Avaliação da dureza superficial pelo esclerômetro de reflexão. Método de Ensaio,

${ }^{27}$ No Brasil $\square_{c}=1,4$ enquanto na maioria das normas internacionais $\square_{c}=1,5$.

${ }^{28}$ No método semi-probabilista de introdução da segurança no projeto estrutural, adotado na $N B R$ 6118, as ações (cargas) e as resistências, com suas correspondentes solicitações atuantes e resistentes, são consideradas variáveis aleatórias que podem ser representadas pela distribuição de extremos e a de Gauss, respectivamente, sendo introduzidos coeficientes de ponderação para "representar" outras variáveis. Na prática somente as resistências dos materiais são variáveis aleatórias a serem medidas e quantificadas durante o processo de execução e uso da estrutura, pois as cargas estão pré-fixadas em tabelas e textos normativos. 
Revista ALCONPAT, Volumen 1, Número 1, Enero-Abril 2011, Páginas 64 - 89

${ }^{29}$ Definição universalmente aceita e que consta da NBR 6118:2007 Projeto de Estruturas de Concreto. Procedimento.

${ }^{30}$ Em geral considera-se tolerável até $10 \%$ abaixo do $f_{c k}$. Até esse limite de $0,9 f_{c k}$ é usual ser dispensável a revisão de cálculo e o reforço da estrutura. Caso os resultados dos corpos-deprova e exemplares moldados sejam inferiores a $0,9 f_{c k}$ pode haver necessidade de revisão estrutural e reforço.

${ }^{31}$ Entende-se por ensaio de resistência à compressão de curta duração, o ensaio que dura menos de 15 minutos. Além desse período o resultado passaria a ser afetado pelos efeitos deletérios das cargas de longa duração (efeito Rüsch). Em muitos casos, e este pesquisador assim o faz, a literatura chama esses ensaios de curta duração, de carregamentos ou ensaios "instantâneos".

${ }^{32} \mathrm{~A}$ execução de estruturas de concreto devem seguir as regras clássicas de "bem construir" e os procedimentos prescritos pela NBR 14931:2004 Execução de Estruturas de Concreto. Procedimento.

${ }^{33} \mathrm{Na}$ realidade $\gamma_{c}$ representa várias diferenças entre o valor experimentalmente obtido do ensaio padrão em corpos-de-prova na boca da betoneira, e o valor efetivo da resistência no elemento estrutural na estrutura bem construída. Conforme explicitado no texto da fib $(C E B-F I P)$ bulletin n.2. v.2. July 1999. Structural Concrete, updating CEB/FIP Model Code 90, item 6.3 p. 59 e no da NBR 6118,item 12.1, $\gamma_{c}=\gamma_{c 1} \cdot \gamma_{c 2} \cdot \gamma_{c 3}=1,5$, onde: $\gamma_{c 1} \rightarrow$ representa a variabilidade da resistência do concreto na estrutura em relação à variabilidade da resistência desse concreto dentro da betoneira e pode ser admitido como da ordem de 1,23. $\gamma_{c 2} \rightarrow$ representa a diferença entre a resistência no corpo-de-prova e a resistência do concreto no elemento estrutural e pode ser admitido como da ordem de 1,05. $\gamma_{c 3} \rightarrow$ representa as incertezas na avaliação matemática da capacidade resistente do elemento estrutural $(\mathrm{R})$ devidas a desvios na construção e modelos de cálculo, e pode ser admitido como da ordem de 1,16 . No caso do Brasil poder-se-ia adotar $\gamma_{c l} \approx$ $1,21, \gamma_{c 2} \approx 1,03$ e $\gamma_{c 3} \approx 1,12$.

${ }^{34}$ Admite-se que a menor unidade homogênea de concreto é o volume de concreto de uma betonada, seja de uma betoneira estacionária de 300L, seja de um caminhão betoneira de 12.000L $\left(12 \mathrm{~m}^{3}\right)$. Para isso ser verdade é necessário que o equipamento esteja em perfeitas condições de conservação e que seja operado adequadamente, principalmente quanto ao tempo e giros da betoneira. A máxima variabilidade de resistência (variabilidade do concreto mais variabilidade das operações de ensaio) tolerada num volume de concreto de um caminhão betoneira, expressa pelo coeficiente de variação da curva normal de Gauss, é da ordem de apenas $v_{c}<2,5 \%$. Ao atender o critério de amostrar corretamente o concreto da betonada, através de coletas do concreto da porção do terço médio do volume total, fica subentendido que se busca essa resistência potencial, pois concretos do início da descarga ou do seu final podem ter resistência com maior variabilidade, tanto para mais como para menos. Sempre cabe ressaltar que não há como elevar a resistência do concreto a não ser alterando o traço. Portanto quaisquer erros de amostragem e ensaio, tenderão a reduzir esse valor potencial, jamais aumentá-lo, a não ser por má fé ou erro humano grosseiro.

${ }^{35}$ a NBR 12655:2006 prescreve os tamanhos máximos de lotes de concreto, em volume, a serem considerados de cada vez. Evidentemente o tamanho mínimo de lote possível coincide com a menor unidade de produto, ou seja, com o volume da betonada. Uma vez conhecidas as resistências de todas as betonadas, o universo dos resultados é conhecido e não há mais necessidade de aplicar estimadores (modelos matemáticos utilizados para inferência estatística).

${ }^{36}$ NBR 7680: 2007 Concreto: Extração, preparação, e ensaios de testemunhos de concreto. Procedimento. 
${ }^{37}$ Observa-se que para fins de resistência de estruturas de concreto, de aço, de pedras e de alvenaria cerâmica, qualquer duração da carga acima de 15 minutos é considerada de longa duração.

${ }^{38}$ Paulo Helene. A Resistência do Concreto sob Carga Mantida e a Idade de Estimativa da Resistência Característica. São Paulo. Anais: III Simpósio EPUSP sobre Estruturas de Concreto. São Paulo, Dez. 1993. p. 271-282

${ }^{39}$ Certos pesquisadores consideram que são 3 (três) coeficientes. Que além dos dois betas citados ( $\square_{1}$ e $\square_{2}$ ) ainda deveria ser considerado um terceiro coeficiente que levasse em conta a diferença entre um corpo-de-prova cilíndrico de $\mathrm{h} / \mathrm{d}=2$ para um pilar que teria geometria diversa desta. Esses pesquisadores atribuem a este coeficiente valores de $2 \%$ a $5 \%$, sem especificar qual a geometria do pilar, qual a direção de extração, qual a dimensão do corpodeprova ou do testemunho, etc. Por ser um coeficiente muito vago, de difícil medida experimental, foi aqui desprezado frente às demais variáveis em jogo, mais objetivas e de maior importância.

${ }^{40}$ item 17.2.2 da NBR 6118:2007.

${ }^{41}$ Hubert Rüsch. Researches Toward a General Flexural Theory for Structural Concrete. ACI Journal, July 1960. p. 1-28

${ }^{42}$ CEB-FIP Model Code 90. Design Code. Bulletin d'Information 213/214, May 1993. O mesmo modelo foi adotado pela nova versão do fib(CEB-FIP) Model Code 2010

${ }^{43}$ Não há consenso sobre o que significa carga significativa. Sabe-se que se o concreto estiver descarregado, por exemplo um corpo-de-prova na câmara úmida, a resistência vai sempre crescer livremente. Se estiver muito carregado (da ordem de 0,7 de sua resistência $f_{c}$ de ensaio "instantâneo"), sua resistência vai subir menos pois estará sendo reduzida pelo efeito Rüsch, ou seja estará sendo reduzida pelo mecanismo da "perda de capacidade resistente por efeito da carga de longa duração". Este pesquisador propõe que abaixo de $0,4 f_{c}$ não há efeito notório da "perda de capacidade resistente por efeito da carga de longa duração" e acima desse valor ela é integral. Trata-se apenas de uma simplificação de bom senso, ainda sem comprovação experimental.

${ }^{44}$ Nils Petersons. Recommendations for Estimation of Quality of Concrete in Finished Structures. Stockolm. Materials et Constructions, v.4, n.24, 1971. p. 379-97

${ }^{45}$ D.P. Maynard \& S.G. Davis. The Strength of "in situ" Concrete. London. The Structural Engineer, v. 52, n. 10, Oct. 1974. p. 369-74

${ }^{46}$ Adolfo Delibes Liniers. Análisis de la Influencia de algunas Variables en la Extracción y Ensayo a Compresión de Probetas Testigos de Hormigón. Madri, Instituto Eduardo Torroja. Informes de la Construcción, n. 266, 1974. p. 65-79

${ }^{47}$ José Orlando Vieira Filho: Avaliação da Resistência à Compressão do Concreto através de Testemunhos Extraídos: Contribuição à Estimativa do Coeficiente de Correção devido aos Efeitos do Broqueamento. São Paulo, Universidade de São Paulo, Escola Politécnica, Programa de Pós Graduação em Engenharia Civil, Departamento de Engenharia de Construção Civil, 2007. (tese de doutorado)

${ }^{48}$ F. M. Bartlett \& J. G. MacGregor. Equivalent Specified Concrete Strength from Core Test Data. ACI, Concrete International, v.17, n.3, Mar. 1995. pp.52-8

${ }^{49}$ Ruy Alberto Cremonini. Análise de Estruturas Acabadas:Contribuição para a Determinação da Relação entre as Resistências Potencial e Efetiva do Concreto. São Paulo, Universidade de São Paulo, Escola Politécnica, Programa de Pós Graduação em Engenharia Civil PPGEC, Departamento de Engenharia de Construção Civil, Jul. 1994. (tese de doutorado)

${ }^{50}$ Portanto um valor que exceda mais do que isso em relação à média, deve ser olhado com atenção e dúvida pois tem uma probabilidade muito pequena de ocorrer. 
${ }^{51}$ Um testemunho de $10 \mathrm{~cm}$ de diâmetro com $\mathrm{h} / \mathrm{d}=2$, num pilar de $40 \mathrm{~cm}$ por $40 \mathrm{~cm}$ de seção transversal vai reduzir a seção resistente de concreto em mais de $16 \%$, Um testemunho de $7,5 \mathrm{~cm}$ reduzirá de mais de $8,8 \%$. Em qualquer caso é muito! Deve-se reduzir ao mínimo o número de testemunhos por pilar. Caso o concreto de uma mesma betonada tenha moldado vários pilares, evitar extrair de todos os pilares escolhendo apenas 2 ou 3 pilares e extraindo um testemunho de cada um deles e analisando os resultados sob o conceito de testemunhos "irmãos" e representativos de uma mesma betonada (conceito de exemplar).

${ }^{52}$ Em geral, nesta etapa do processo, dá-se preferência aos resultados dos testemunhos extraídos pois estes representam melhor o componente estrutural. 